\title{
On-Chip Energy Harvesting for Implantable Medical Devices
}

\author{
Viera STOPJAKOVA, Martin KOVAC, Miroslav POTOCNY
}

Dept. of IC Design and Test, Institute of Electronics and Photonics, Faculty of Electrical Engineering and Information Technology, Slovak University of Technology, Ilkovičova 3, 81219 Bratislava, Slovakia

viera.stopjakova@stuba.sk

Submitted April 21, 2020 / Accepted May 5, 2020

\begin{abstract}
The paper brings an overview of main challenges in implantable medical devices (IMD) research area, where the main objective of discussion covers wireless power transferring (WPT) systems as the hot topic dedicated to energy harvesting that is still gaining in popularity. The paper is focused on electromagnetic-transfer principle, where full integration of the WPT systems on a chip is taken as the primary goal covering passive transducer and rectifier implementations. The presented research reveals many issues raised from the state of the art solutions. These solutions can or should be detailed investigated in the future research. Therefore, this paper discusses about so far hidden potential of fully integrated WPT systems, where both near-field and farfield approaches are included. Additionally, the discussion is also extended to a principle of power transfer efficiency (PTE) maximization through approaches such as matching and finding the optimal source/load together with rectifying and regulating issues.
\end{abstract}

\section{Keywords}

Wireless power transferring systems, energy harvesting, fully on-chip WPT implementation, electromagnetictransfer principle, on-chip antennas

\section{Introduction}

Advanced modern technologies of integrated circuit (IC) fabrication are characterized by not only high density of circuit elements but also the support of heterogeneous systems such as systems-on-chip (SoC) including radio frequency (RF) structures and compatibility of micro-electromechanical systems (MEMS) in the post-processing steps. In other words, IC research area has a promising potential to deal with selected issues of energy harvesting (EH) and contribute to the entire system miniaturization. Just miniaturization (in addition to the energy consumption) belongs to one of the most critical task in medical applications such as IMDs or grown in popularity active implanted medical devices (AIMDs). AIMDs according European Union direc- tive 90/385/EHS extend definition of active medical device (AMDs) that originally says: "AMD is any medical device relying for its functioning on a source of electrical energy or any source of power other than that directly generated by the human body or gravity." This part of the definition is important in terms of necessity for a permanent battery power source, which is partially in conflict with the recent trend of full energy autonomy by replacing them with internal $\mathrm{EH}$ systems. Such devices recycle renewable energy from environment and are usually, but no necessarily, implemented as MEMS in order to ensure their compactness [1-5].

Nowadays, many internal EH systems are still not capable to completely fulfill power requirements of energyhungry electronic systems under the full operation conditions. Unfortunately, tens (rarely slightly above hundreds) of $\mu \mathrm{W} / \mathrm{cm}^{2}\left(\mathrm{~cm}^{3}\right)$ of available non-time-deteriorated power per area (volume) densities can be expected in the most optimistic case for medium and deeply implanted IMDs not based on strong kinetic movement such as waving of limbs [6-9]. In the case of internal energy harvesting, researchers are looking for solutions especially in fuel-cell based harvesters with encouraging results of thousand of $\mu \mathrm{W} / \mathrm{cm}^{2}$ in peak but at the cost of significant gradual degradation over time [8]. However, to compare the power available from internal energy harvesters with specifications of selected medical devices and applications (Tab. 1), one can conclude that the current solutions only recline in mutual intervention of internal harvesters and a battery like the power source. Such approach inevitably negatively impacts the lifetime of IMDs. Perhaps, the only potential exception includes heart-function stimulus and monitoring system, and low-duty cycled operating devices.

From IMD trends point of view, the alternative could be implementation of external energy harvesters (known as wireless power transfer - WPT EHs), and especially those based on acoustic and conduction (for medium and deep implantation depths), then optic, electric and electromagnetic principle (for shallow or subcutaneous implantations) [3,9, 12-20]. All of them can be realized as relatively planar structures and selected ones directly benefit of their semiconductor nature. Therefore, there is a huge 


\begin{tabular}{|c|c|c|c|}
\hline Application & Power & Communication & Energy Source \\
\hline $\begin{array}{c}\text { Pacemaker, } \\
\text { Cardioverter-defibrillator }\end{array}$ & $\begin{array}{l}\leq 10 \mu \mathrm{W} \\
\leq 100 \mu \mathrm{W} \\
1-10 \mu \mathrm{W}\end{array}$ & inductive link & primary battery, 10 -year lifetime \\
\hline Hearing aid & $100-2000 \mu \mathrm{W}$ & telecoil & rechargeable battery, 1-week lifetime \\
\hline $\begin{array}{l}\text { Analog cochlear processor, } \\
\text { Cochlear implants }\end{array}$ & $\begin{array}{c}200 \mu \mathrm{W} \\
1-10 \mathrm{~mW}\end{array}$ & inductive link & rechargeable battery, 1-week lifetime \\
\hline Neural implants & $\begin{array}{c}1-10 \mathrm{~mW} \\
1-100 \mathrm{~mW} \\
10-200 \mathrm{~mW}\end{array}$ & high-rate inductive link & external battery,inductive power \\
\hline Retinal implants & $\begin{array}{c}200 \mathrm{~mW} \\
40-250 \mathrm{~mW} \\
1-100 \mathrm{~mW}\end{array}$ & high-rate inductive link & external battery,inductive power \\
\hline Insulin pump & $10-50 \mu \mathrm{W}$ & - & - \\
\hline WBAN monitoring & $\begin{array}{c}140 \mu \mathrm{W} \\
\leq 100 \mu \mathrm{W} \\
\end{array}$ & far-field wireless link & primary battery \\
\hline Artificial heart & $10-100 \mathrm{~W}$ & - & external source, inductive power \\
\hline
\end{tabular}

Tab. 1. Specifications of selected medical devices and applications [7, 8, 10, 11].

potential in direct full implementation in a standard CMOS process (omitting acoustic harvesters as primarily MEMS based ones), which turns out to be greatly attractive in terms of many benefits such as miniaturization, increase of system and packaging reliability, low-cost solution, omitting post-processing steps, etc. All these advantages become the driving force towards integration of the entire $\mathrm{EH}$ into a chip, where the choosing of an adequate WPT approach for the final application depends directly on specific requirements of the system itself such as energy density, depth of IMDs implantation, necessity for out-of-body energy-transport, and so on.

\section{EM-Based WPT Systems}

From the global perspective of WPT systems, the electromagnetic (EM) transfer energy systems based on near reactive and radiative field (reactive near field means magneticbased coupling) belongs to the most popular ones. Here, one can expect typically tens of $\mathrm{mW}$ with $\eta>50 \%$ and from tens of $\mu \mathrm{W}$ to ones of $\mathrm{mW}$ with $\eta<10 \%$ in a case of fully discrete system (size $\geq 10 \times 10 \mathrm{~mm}$ ) and more compact version (size $\leq 10 \times 10 \mathrm{~mm}$ ), respectively [17], [18]. Such an approach enjoys tremendous popularity also in powering of many market products such as Activa RC Neurostimulator, Eon Mini Rechargeable IPG or others. These results were achieved trough a long history and with an extensive research accompanied by the relatively simple design and implementation. This simplicity is anchored mainly in:

- The straightforward implementation chain of WPT individual circuit blocks (Fig. 1).

- Neglecting (without introducing significant error) of parasitic effects of the transfer media itself in operation with the frequency range well below $100 \mathrm{MHz}$. Such parasitic effects contribute to the attenuation of EM wave (material loss) and multiple reflection at individual tissues interfaces (reflection loss), which start to be already notable above $100 \mathrm{MHz}$ [21].
However, while the full-integration effort of energy harvesters remains relatively untouched, the second item mentioned above must go through serious investigation due to inevitable pushing the operation frequency to the considerably higher values (if compared to commonly used discrete solutions). Generally, from far-field point of view, higher frequency value improves not only radiation efficiency but also impedance matching capability. On the other hand, in the near-field case, increasing rate of magnetic intensity change also often contributes to the improvement of the PTE in terms of getting a passive rectifier into better working conditions. But one has to keep in mind that increasing the frequency also increase losses in tissues. Therefore, amount of the transferred power required for correct IMDs operation strongly depends on PTE under the supervision of health hazard limits such as specific absorption rate (SAR), local maximum induced electric field strength $E$, and current density $J$ [21], [22]. It is obvious that the only way how to bring power hungry IMDs to life without violation life-threatening limits lies in the PTE enhancement. Being aware of this, the paper brings analysis of selected issues (associated with on-chip energy harvesters) divided into the following three sections: Sec. 2.1: On-chip EM Transducer, Sec. 2.2: Rectifiers and PTE, and Sec. 3: WPT Design Example. It should be noted that attention will be primarily focused on-chip EM transducer and everytime when talking about on-chip antenna (OCA) we will refer to a passive structure designed and implemented together with the active part of the system in a single chip (known as SoC).

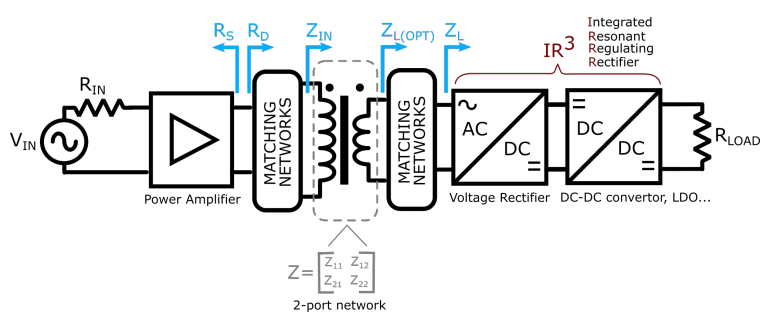

Fig. 1. Block diagram of the power transfer in a point-to-point WPT system with control management on the receiving side. 

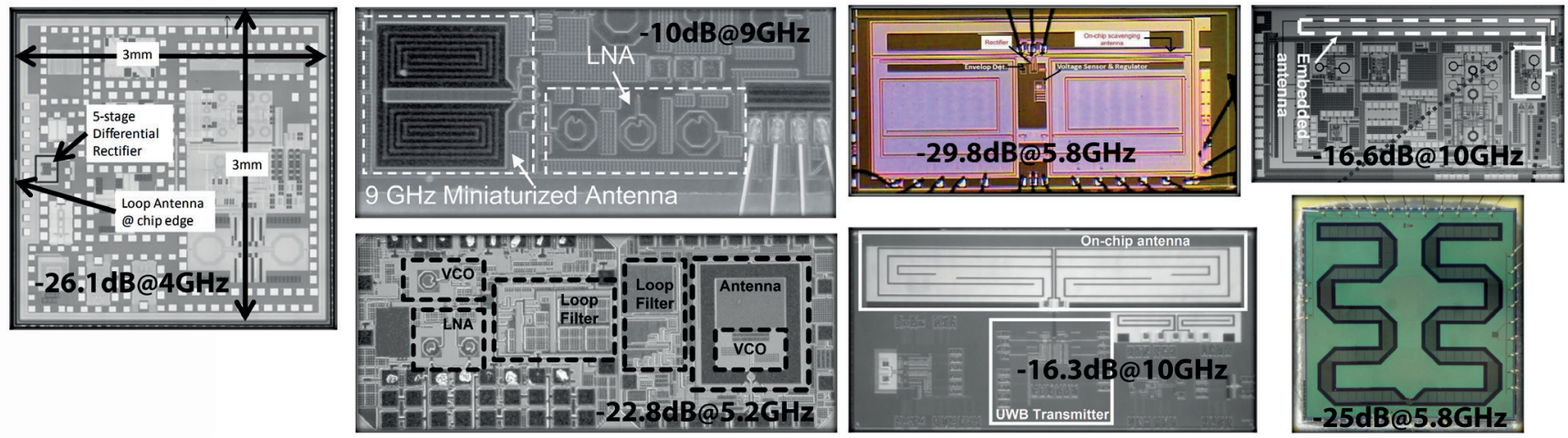

Fig. 2. Example of OCAs realized in standard CMOS process [23-30].

\subsection{On-Chip EM Transducer}

\subsubsection{Far-Field OCA}

As indicated above, for on-chip antenna realization, the standard operational frequency is shifted up to tens of $\mathrm{GHz}$ and more to preserve the antenna performance features (e.g. convenient handling of matching condition, reasonable radiation gain, etc.) which originated from physical requirements. However, in the case of IMDs, using frequency values above $\mathrm{GHz}$ boundary can be impractical since the attenuation constant of lossy tissue increases rapidly with frequency [31]. The different challenges of a discrete version of the implanted antenna ( [32]) and the OCA ( [33], [34] or Fig. 2.) in IMDs research are obvious. For example, while in the discrete form in the case of MISC $(402-405 \mathrm{MHz})$ and ISM $(2.45 \mathrm{GHz})$ antennas, relatively reasonable gain $(\approx-30 \mathrm{dBi})$ can be achieved for $2-3 \mathrm{~cm}$ implantation depth, the OCA solution suffers from radically poor performance, where in lower limit of $5 \mathrm{GHz}$, not more than $-20 \mathrm{dBi}$ antenna radiation gain (that drops sharply towards lower frequencies) is usually reached by common way. Moreover, if a path loss will be contemplated, additional decrease about $8 \mathrm{~dB} @ f=2.4 \mathrm{GHz}$ and $25 \mathrm{~dB} @ f=5 \mathrm{GHz}$ should be expected [35]. Such an observation about the total gain of $-45 \mathrm{dBi}$ seen from outside environment makes the OCA highly impractical for middledepth IMDs applications, where PTE at least around 1\% is recommended. The more perspective situation is in the case of subcutaneous implant devices, where the same discrete antennas are capable to deliver power with the PTE greater than $1 \%$.

From this brief discussion, it is obvious that only modification of OCA structures based on techniques for electrically small antennas [36] or implementation of only elementary, physically design-based feasible techniques to reduce the impact of high-loss substrate (e.g. incorporation of a shielding layer [26], [37]) are insufficient for such desired frequencies $(<5 \mathrm{GHz})$ in a standard CMOS process. In addition, significant nuisance is caused by the following:

1. Absence of progressive techniques (lens forming, dielectric or cavity based resonator, waveguide technique, HIS/AMC or superstrate structures, micro-machining, etc. [33, 37-43]) because of physical requirements or additional post-processing steps.

2. Limiting physical space for the OCA realization.

3. Presence of low resistivity substrate $(5-20 \Omega)$, which is critical because electrically small antennas are characterized by high quality factor, and therefore, intensive reactive near field.

Therefore, it can be stated that for the intention to integrate the OCA antennas into IMDs applications, it is essential to find an alternative solutions or techniques to existing ones that would offer promising results.

One of the unconventional ways that we have investigated for OCA design, draws on idea of packaging the IC chip together with the OCA by so-called matching insulation layer (MIL) that can reborn the GHz frequency spirit by significant improvement of the radiation efficiency (Fig. 3). MIL concept was built on the following two main observations:

- observation based on application of a specific material with high relative permittivity (dielectric resonator or superstrate structure) and assessing its impact on OCA properties,

- observation based on close native analogy between packaging material of IMDs and a matching layer.

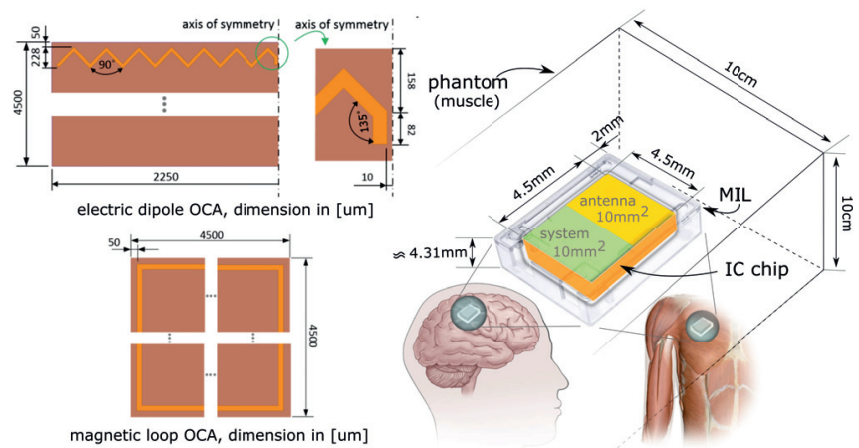

Fig. 3. Proposed concept based on MIL for IMDs. 
For example, in the case of a dielectric resonator, it has been shown that $\varepsilon_{\mathrm{r}}$ in the range of values $40-60$ at frequency $\approx 28 \mathrm{GHz}$ contributes to reducing the influence of a low-resistance substrate leading to increased radiation efficiency and gain, which is caused by the "trapping" of the electromagnetic field primarily in electrically denser environment (dielectric resonator) rather than in individual modes of surface/substrate waves [42], [43]. In the case of superstrate structure application with a high $\varepsilon_{\mathrm{r}}$, a positive effect on the radiation efficiency of the microstrip antenna (and also its vertical compaction) has been observed [44]. Horizontal compaction can be observed from the theory of conduction in multi-layer structures, where the incorporation of a material with a relative $\varepsilon_{\mathrm{r}}>1$ increases the effective permittivity of the waveguide and thus, shortens the wavelength of electromagnetic waves travelling through them. The second point is aimed at especially to work of Mr. Merli and Dissanayake that prove that the incorporating material with suitable properties between a lossy tissue and antenna leads to negotiability improvement of the antenna performance. Including the previous discussion and all the findings [32,45,46], the gained knowledge essential for OCA and IMDs negotiability can be summarized into the following points:

1. Reduction of direct contact between the radiating element and the lossy environment contributes to an overall system improvement.

2. In the low-resistance substrate, the implementation of the super-stratified layer or dielectric with high $\varepsilon_{\mathrm{r}}$ positively affects the radiation properties of on-chip antennas and contributes to their overall compactness.

3. Inclusion of a dielectric insulating layer in the design leads to a reduction of insertion losses from the IMD perspective.

4. $\varepsilon_{\mathrm{r}}$ of both interfaces (tissue-MIL) should be the same or at least approximately the same (high $\varepsilon_{\mathrm{r}}$ of the soft tissue and hence the MIL results in a shifting of the reflection coefficient $\Gamma$ to lower values and lower frequencies).

5. The MIL thickness should be maximized, but in reasonable manner not to endanger human health,

6. as a source of excitation of electromagnetic radiation it is better to use magnetic source rather than electrical one.

7. Negligible variability of $\Gamma$ depending on the change in the conductivity of the tissue (the conductivity of the insulator was considered zero) in contrast to the considerable variability associated with a lack of consistency in $\varepsilon_{\mathrm{r}}$ of individual interfaces.

The powerful and great potential of the abovementioned observations can be clearly observed in Fig. 4 that originated from idea presented in Fig. 3 with incorporation of a lossless MIL with $\varepsilon_{\mathrm{r}}=50$. This graph shows results obtained from numerical simulations without the presence of lossy tissue, where properties of TSMC CMN90 fabrication process is considered and both OCAs are designed at AL-RDL (top) layer. It can be observed that the radiation efficiency of simple electric and magnetic dipoles quite

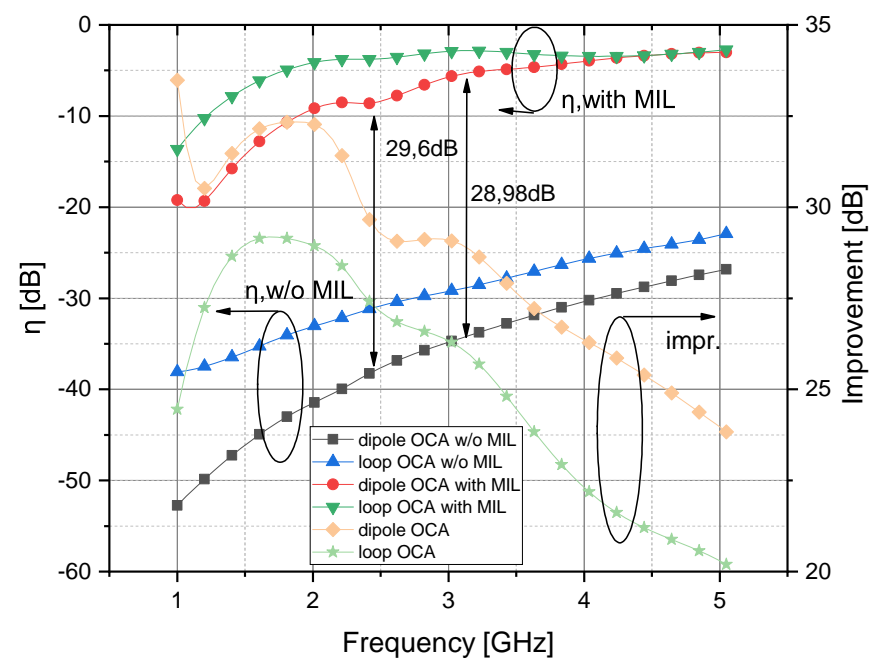

Fig. 4. The demonstration of promising OCA concept based on MIL for IMD application.

copies the performance of the published solutions from Fig. 2 (air as surrounding environment). It is obvious that a poor performance that drastically decreases with lowering frequency. However, if the MIL concept is considered, the situation significantly changes in favor of promising results. For example, roughly about $30 \mathrm{~dB} @ f=2.4 \mathrm{GHz}$ (1000times) improvement with $\eta>-10 \mathrm{~dB}$ was observed and so in conjunction with knowledge about $8 \mathrm{~dB} @ f=2.4 \mathrm{GHz}$ path loss, the proposed concept (in issue of EHs based on far-field OCA) potentially can opens the door for low-depth implantation devices with theoretical efficiency close to $1 \%$. Moreover, theoretically the concept does not need extra postprocessing steps (in comparison to [47]) except for the packaging process itself.

\subsubsection{Near-Field OCA}

From the above discussion, one could conclude that $\mathrm{GHz}$ radiative far field is impractical for IMDs in terms of high attenuation of electromagnetic wave in a soft tissue and moreover, OCAs suffer for significant performance degradation under $\mathrm{GHz}$ boundary (seen as slope changes in Fig. 4). To deal with this issue, another solution has been carried out to get reasonable PTE while still being compatible with a CMOS process, and to fully retain the idea of miniaturization. The new trend has gained momentum especially in the last decade and is based on near field and magnetic coupling fundamentals (Tab. 2). Similar to the far-field research area, the main motivation is to achieve compactness, affordable price and reliability at the best possible performance of the WPT systems including OCA (in this case, OCA refers to strictly passive-inductive based structure with the ability to couple an external magnetic field, simply coil). Besides a pure MEMS implementations [48], there exist attempts to implement an antenna in the form of a coil directly on a silicon chip but this requires additional steps in a manufacturing process such as micro-machining [49]. It is also possible to use the process of contacting itself in the implementation of bonding coil with $L=103.7 \mathrm{nH}, Q=24.25$ at $147 \mathrm{MHz}$ [49], [50]. In general, such approaches lead to 
the better system performance, however for the prize of increasing reliability risk that belongs to the most important requirements when speaking about IMDs. Therefore, implementation effort in the recent years aims at OCA realization especially.

Nowadays, there are two leading trends in near-field applications with integrated OCA, marked according to [58] as resonant inductive coupling: a) long-fledged high-frequency $(\geq 850 \mathrm{MHz})[51,52,56,57]$ based on radiative near field; and b) raising up lower-frequency $(\leq 500 \mathrm{MHz})[22,53,55$, 59-61] alternative that dominantly draws from benefits of reactive near field. The lower-frequency approach grows in interest especially due to success of Zargham's two-port theory of the PTE maximization [62]. Table 2 shows selected works that reflect the state-of-the-art EHs implemented directly on a chip, where the attention was aimed at biomedical applications. One can observe that the systems with an integrated OCA (usually called rectennas to emphasize direct purpose of conversion to the output DC level) realized in a standard CMOS process are in general characterized by PTE not exceeding $1 \%$ for distance about $1 \mathrm{~cm}$ in practice, where weak coupling mostly determine the final performance of WPT systems. Traditionally, a coupling is increased by additional intermediate coil or multiple coils where for instance, so called booster antenna seen to be relatively perspective [63]. However, their implementation in IMDs is quite restrictive. Additionally, from Tab. 2 it can be stated that the use of lower frequencies (about hundreds of $\mathrm{MHz}$ ) contributes to the effective design of WPT in case of EHs realized directly on the lossy chip, where huge loss in power efficiency through losses of the silicon substrate plays the main role [62]. The formula ( 1) reflects this phenomenon, where $\sigma_{\mathrm{SUB}}$ is substrate conductivity, $A$ represents inner area of coil, $B_{\mathrm{C}}$ is magnetic field at center of coil, $t_{\mathrm{SUB}}$ is the substrate thickness and $\omega^{2}$ means angular velocity that contributes to losses with factor of power of 2 [64]. The equation also reflect direct relationship between substrate conductivity and thickness. Taking this into account, the superior performance of SOI (Silicon-On-Insulator) realized WPTs has a logical reason. Additionally, using the lower band of a frequency range also contributes to SAR reduction as a complement to other techniques like including metamaterial, segmentation of an external antenna, etc. [22].

$$
R_{\mathrm{SUB}, \mathrm{ED}}=\frac{\sigma_{\mathrm{SUB}} A^{2} B_{\mathrm{C}}^{2} t_{\mathrm{SUB}}}{16} \omega^{2}
$$

Investigation of the WPT system itself in terms of highlevel mathematical description (e.g. effect of basic matching configuration to PTE) to improve the power transfer performance is well extended. However, detailed insight into individual phenomenons (eddy current, proximity effect, coupling capacities, density of metal filling, etc.), which affect properties of an OCA-coil working under $500 \mathrm{MHz}$ together with the implementation of suitable layout techniques suffer from a lack of results, where only very few works are aimed at OCA-coil design strategies $[22,59,62]$. All of them agree with the statement that the optimal design of integrated WPT systems depends not only on its structure but also on the external conditions and load, where the initial interest should focused primarily on the transducer design under knowing of $Z_{\mathrm{L}(\mathrm{OPT})}($ see Fig. 1). The known design strategies include:

- Mr. Park et al. [59] suggest to start the process of maximization quality factor $Q$ thought the optimum turn width/space ratio after selection of right number of turns in the horizontal plane that is usually in the range of 1-3 [59], [62].

\begin{tabular}{|c|c|c|c|c|c|c|c|}
\hline & {$[51]$} & [52] & [53] & [54] & {$[22],[55]$} & [56] & [57] \\
\hline Year & 2013 & 2016 & 2018 & 2013 & 2013,2015 & 2017 & 2016 \\
\hline Application & EH, RFID tag & $\mathrm{EH}$ & EH & EH & $\mathrm{EH}$ & $\mathrm{EH}$ & RFID tag \\
\hline $\begin{array}{l}\text { Frequency } \\
{[\mathrm{GHz}]}\end{array}$ & 1.5 & 0.95 & 0.434 & 5.2 & 0.16 & 2.75 & 0.986 \\
\hline CMOS process & $65 \mathrm{~nm}$ & $45 \mathrm{~nm} \mathrm{SOI}$ & $180 \mathrm{~nm} \mathrm{SOI}$ & $180 \mathrm{~nm}$ & $130 \mathrm{~nm}$ & $180 \mathrm{~nm} \mathrm{SOI}$ & $180 \mathrm{~nm}$ \\
\hline $\begin{array}{l}\text { EH chip } \\
\text { dimension } \\
{[\mu \mathrm{m}]}\end{array}$ & $500 \times 250$ & $550 \times 700$ & $2000 \times 2000$ & $3200 \times 1500$ & $2000 \times 2180$ & $1600 \times 1600$ & $1500 \times 1500$ \\
\hline Distance $[\mathrm{mm}]$ & 1 (air) & $\begin{array}{c}40 \text { (air) + } \\
10 \text { (chicken) }\end{array}$ & 10 (air) & $\begin{array}{l}30 \text { (air) + } \\
5 \text { (saline) }\end{array}$ & $\begin{array}{c}2.5 \text { (air) + } \\
7.5 \text { (muscle) }\end{array}$ & $\begin{array}{c}10 \text { (air) + } \\
10 \text { (chicken) }\end{array}$ & 15 (air) \\
\hline Quality factor & 8 & NA & 14.18 & NA & $\begin{array}{c}11.05 @ 101 \mathrm{MHz} \\
8.5 @ 160 \mathrm{MHz}\end{array}$ & NA & 20.8 \\
\hline $\begin{array}{l}\text { Inductence } \\
{[\mathrm{nH}]}\end{array}$ & 18 & NA & 7.3 & NA & $\begin{array}{l}65 @ 101 \mathrm{MHz} \\
90 @ 160 \mathrm{MHz}\end{array}$ & NA & NA \\
\hline $\begin{array}{l}\text { Output power/ } \\
\text { max. efficiency }\end{array}$ & $\begin{array}{c}10.5 \mu \mathrm{W} @ \\
P_{\mathrm{in}}=17 \mathrm{dBm} / \\
-34.5 \mathrm{~dB}\end{array}$ & $\begin{array}{c}50 \mu \mathrm{W} @ \\
\text { EIRP=36dBm/ } \\
\text { NA }\end{array}$ & $\begin{array}{c}138 \mu \mathrm{W} @ \\
P_{\mathrm{in}}=17 \mathrm{dBm} / \\
-21.7 \mathrm{~dB}^{*},-25.6 \mathrm{~dB}\end{array}$ & $\begin{array}{c}\text { NA@ } \\
\text { EIRP=37 dBm/ } \\
\text { NA }\end{array}$ & $\begin{array}{c}56 \mu \mathrm{W} @ \\
\mathrm{NA} / \\
-20.96 \mathrm{~dB}\end{array}$ & $\begin{array}{c}1.21 \mathrm{~mW} @ \\
\mathrm{NA} / \\
-26.46 \mathrm{~dB}\end{array}$ & $\begin{array}{l}\approx 1 \mathrm{~mW} @ \\
\mathrm{NA} / \\
-25.4 \mathrm{~dB}\end{array}$ \\
\hline $\begin{array}{l}\text { Output voltage } \\
{[\mathrm{V}]}\end{array}$ & 0.7 & 1 & 1.08 & 1.15 & 3.1 & 1.1 & NA \\
\hline
\end{tabular}

Tab. 2. Selected energy harvesters with on-chip antennas. 
- Mr. Zargham et al. [59] implement various methods for $Q$ and $L$ investigation through techniques such as vertical parallelization of metal layers or applying a multilayer structure depending on specific conditions on the principle of the optimum load. In doing so, Zargham proceeded from the requirement of eliminating a possible additional matching coil (e.g. a part of PI, L matching block, etc.) and targets matching realization (to fulfil the optimum load condition $Z_{\mathrm{L}(\mathrm{OPT})}$ ) only by an on-chip resonant capacitor.

- When the optimum load condition is met, the aim of WPT design is to maximize the mutual inductance of the primary and a secondary coil (maximizing $L$ and $Q$ ) while reducing their resistance (maximizing $Q$ but only if the optimum load condition persist inviolate) [22], [62].

As already mentioned, the missing detailed investigation of various OCA-coil designs in sub-500 MHz frequency band can open a new space in the issue of fully-integrated energy harvesters for IMDs. For instance, in the case of $\mathrm{GHz}$ frequency and classic approach to coil design (designed for a specific inductor value), the effect of changes into the coil structure are well described and characterized. However, without doubt, one of the main goals of OCA-coil design for energy harvesting is to maximize the inductance, i.e. mutual coupling (or better maximize $Q L$ product under the optimum load condition). Besides that, if the $\mathrm{MHz}$ frequencies are in interest, the other parasitic effects can become dominant. It has been proven that different techniques (e.g. horizontal and vertical traces tapering, multi-layering, multi-stacking, cutting a wide conductor into slices, techniques for proximity effect reduction and many others) affect the quality, inductance and self-resonance frequencies, and can be used to tune the PTE to its maximum for desired load conditions. Nevertheless, the main question remains: "How much benefits can bring these techniques in EH applications with an OCA-coil and few hundreds of $\mathrm{MHz}$ operation frequencies?"

Good early insight into situation can bring these three examples:

1. If we look little bit closer at the issue of OCA-coil structure, the interesting observation has been carried out by Park et al. where careful design of an OCAcoil (e.g. tapering technique) and layout manipulation (H-tree signal distribution) bring very promising experimental results of the PTE about 4\% (1 mm air $+10 \mathrm{~mm}$ tissue) with possible improvement up to nearly $9 \%$ in the case of air as the transfer medium [59].

2. Multilayered turns technique is in general characterized by a high resistance value caused by proximity affect and extremely small distance of stacked (vertically parallel) conductors $(<1 \mu \mathrm{m})$. In the case of 3-layer conductor configuration, $1 \mathrm{GHz}$ frequency and $20 / 1$ width/space ratio increasing the resistance per length about $50 \%$ has been recorded in comparison to an individual wire and is much significant than the side-by-side configuration [65]. This phenomenon together with the skin effect are even more dominant when a wider conductors are used [66]. Just method of using a wide conductor can be found in many recent publications $[22,56,59,62]$.

3. Most of investigated OCA-coils are based on a simple spiral coil structure. However, it is well known that the symmetrical structure in general can be more beneficial [67], [68]. This observation was proved also for sub-500 MHz frequency band where improvement of $Q$ by about $24 \%$, and $L$ value improvement by $34 \%$ were reported [69]. Figure 5 brings additional information about the investigated coil structure in the form of experimental verification, where significant performance degradation is observable compared to simulation results. This is mainly caused by high density of metal coverage (with loop-based nature) and semiconductor active devices in the core of coils that is not the case in the conventional design of specific inductor value in $\mathrm{GHz}$ frequency band.

As can be seen from the previous examples, some of the rules copied from the RF inductor $\mathrm{GHz}$ design can be valid also for sub-500 MHz frequency band and some of them may raise some doubts requiring a deeper investigation. It is also important to note that using the lower operational frequency and challenging with related issues can bring promising results directly in two individual research branches at the same time. The first one is already discussed OCA-coil-based utilization (power/energy harvesting), while the second one is related to inductor-based utilization in DC-DC on-chip converters (power/energy distribution) [71-74]. Frankly speaking, the targeted research can kill two flies by a single stone.

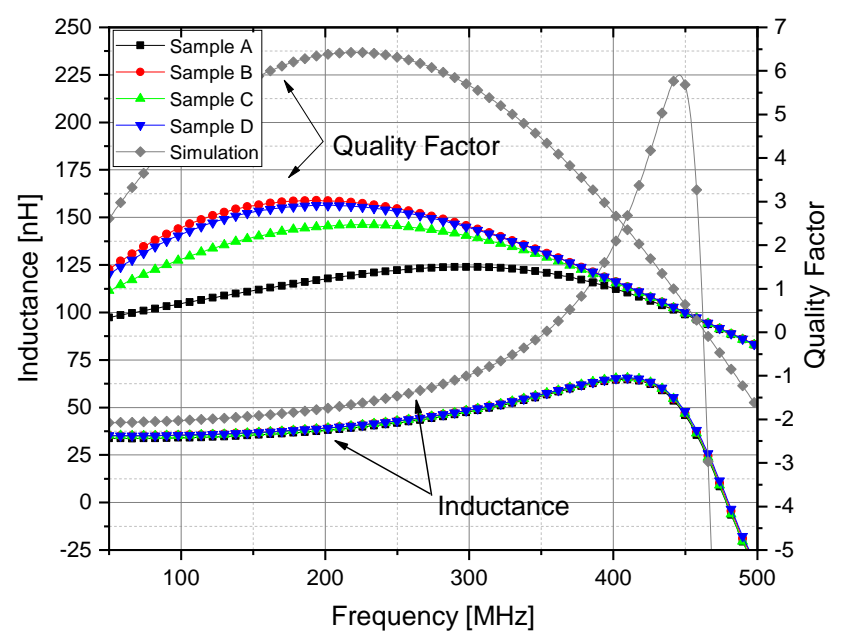

Fig. 5. Performance of a symmetrical OCA-coil for sub$500 \mathrm{MHz}$ frequency band. The layout of the proposed OCA-coil can be found in [70]-Fig. 24. 


\subsection{Rectifier and PTE}

\subsubsection{Rectifier}

The primary objective of a WPT system (as a part of RFID or energy harvester in general) is the maximization of PTE across physical dimensions of antennas, impedance matching (or an alternative related approach) that varies with load impedance, the distance (or implant depth) between device and external source, and also with environment material $[53,57,62,75]$. In other words, the PTE is translated into link, matching, driver and rectifier efficiencies covering entire power flow chain (according to Fig. 1):

$$
\eta_{\mathrm{TOT}}=\eta_{\mathrm{AMP}} \eta_{\mathrm{MC}, \mathrm{T}} \eta_{\mathrm{LINK}} \eta_{\mathrm{MC}, \mathrm{R}} \eta_{\mathrm{REC}} \overbrace{\mathrm{DC}-\mathrm{DC} .}^{\text {regulating rectifier }}
$$

On the receiving side directly behind the OCA, the alternative (AC) signal in nature is harvested. Such a signal must be then rectified and modified to suitable voltage value necessary for ensuring reliable operation of the targeted IMD. In general, we have few options how to deal with it, and those can be categorized into three main groups according to functional realization of the rectifier:

1. active, so called synchronous rectification,

2. passive,

- conventional design without a suppression mechanism of the MOS device threshold voltage $V_{\mathrm{TH}}$

- design based on suppression mechanism of the threshold voltage $V_{\mathrm{TH}}$

- implementations using a transformer with a central terminal

- class-driven design (e.g. E-class rectifier)

3. special, known as a regulating rectifier.

Relatively widespread are active synchronous rectifiers, which use fast comparators and control loops to manage the pass transistors. To our best knowledge, their application for higher frequencies $>100 \mathrm{MHz}$ (expected hunting for ISM $433 \mathrm{MHz}$ realizations failed) and low voltages (in terms of requirements for comparator) WPT systems with high voltage $\eta_{\text {REC-V }}$ and power $\eta_{\text {REC }}$ efficiency seem to be yet unprofitable. Special high-speed comparators are typically characterized by high power consumption (up to hundreds of $\mu \mathrm{W}$ at frequencies in ones of $\mathrm{MHz}$ ), relatively high $\mathrm{AC}$ input voltage (usually at least $1 \mathrm{~V}$ if step-up voltage conversion not included), compensation mechanism for the input offset voltage and loop delay and so on [76-78]. Despite of these unfriendly facts, very promising results of $\eta_{\text {REC-V }}=83 \%$ and $\eta_{\text {REC }}=84 \%$ at $200 \mathrm{MHz}$ that benefit from using a high-speed comparator with simple mechanism of loop delay and input offset compensation were presented

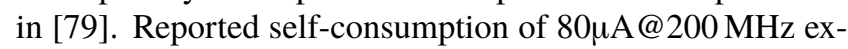
hibits acceptable level.

On the other hand, employing the conventional passive rectifiers belongs to the most popular approaches, which are also feasible for $\mathrm{GHz}$ frequencies (all realizations introduced in Tab. 2 employ a passive rectifier) and low voltage conditions. From low voltage point of view, mainly solutions that suppress the effect of the $V_{\mathrm{TH}}$ and thus reduce the voltage drop across the rectifier are attractive. The $V_{\mathrm{TH}}$ suppression (or precisely said the reducing its effect in MOS transistor control) may be either static or differential (also presented in Sec. 3), and comprehensive overview of the individual principles and their impact can be found in [80]. We only note that one of the most popular principles is the technique using "bootstrap" capacitors. Thanks to this technique, the promising performance even for high frequency applications such as RFID could be possibly achieved [81-85]. For example, in [82], it has been reported $73 \% @ f=950 \mathrm{MHz}$ of $\eta_{\mathrm{REC}}$ for $0.29 \mathrm{~V}(1.25 \mathrm{~V})$ input (output) voltage and the load of $50 \mathrm{k} \Omega$. A special technique is floating gate approach that is however incompatible with a standard CMOS process [86], [87]. An alternative may be a quasi-floating gate design technique that exhibits excellent properties $\left(\eta_{\text {REC }}>66.7 \% @ V_{\text {in }}=0.45 \mathrm{~V}\right.$ under $30 \mathrm{k} \Omega$ load) and can also be used for high-frequency applications $(2.4 \mathrm{GHz}$ in this case) [88]. However, despite of the wide use of passive rectifiers, they suffer from the voltage drop across the rectified diode and also from significant reverse-leakage current (this is not the issue in active rectifiers). This two phenomenons effect the PTE, depending on the input voltage/power on both sides of characteristic. In a lower band, the significant voltage drop is dominant, while in opposite, the leakage issue causes serious problem in the case of increasing the input voltage/power and surprisingly, for decreased frequency (increased time window in which reverse current can flow back into the source) [89]. Therefore, we often see the significant decreasing of PTE on both sides with the cramped optimum point. To achieve a flat PTE curve, the gate-boosting scheme ( $V_{\mathrm{TH}}$ suppression) has to fulfil the following requirements [88]:

- For input levels smaller than the optimum point, positively boost the effective gate-source voltage of the switches (i.e. decrease the effective $V_{\mathrm{TH}}$ of the switches and thus, increase the forward current).

- In the optimum point, preserve the already generated gate voltages, i.e. provide a zero boost in the maximum efficiency point.

- For the input voltages larger than the optimum value, decrease (or negatively boost) the effective gate-source voltage of the switches, i.e. increase the effective $V_{\mathrm{TH}}$ and accordingly reduce the reverse leakage current.

We have to also be aware of the voltage amplitude at rectifier input during design phase that can be estimated for RF far-field application under lossless matching circuits [59], [87] as follows:

$$
V_{\mathrm{IN}}=\sqrt{\frac{\left(1-|\Gamma|^{2}\right) G_{\mathrm{R}} P_{\mathrm{RAD}} \lambda^{2}}{4 \pi}\left(\frac{\eta_{\mathrm{REC}}}{\eta_{\mathrm{REC}-\mathrm{V}}^{2}}\right) R_{\mathrm{IN}, \mathrm{DC}-\mathrm{DC}}}
$$


where individual quantities mean: $\Gamma$ - reflection coefficient from the antenna terminals, $G_{\mathrm{R}}$ - transmitter antenna gain, $\lambda$ - medium wavelength, $P_{\mathrm{RAF}}$ - radiation density around the receiving antenna, $R_{\mathrm{IN}, \mathrm{DC}-\mathrm{DC}}$ - input impedance of the DC-DC converter or a low dropout voltage regulator. The partial solution to flattening PTE curve can be in using the multi-path rectifier [90] or other mechanism that can adaptively manage above mentioned issues.

Very promising performance in low-voltage applications seems to be rectifiers based on a OCA-coil with central terminal, where implementation in the form of a symmetrical structure is not a serious problem (see Sec. 2.1.2). Such a realization can attacks $80 \% @ f=1 \mathrm{GHz}$ level of PTE under the input voltage comparable to the $V_{\mathrm{TH}}$ of rectifying transistors. However, similarly to the previous designs, after achieving the peaks, there is a significant decrease reported [91]. The last group include all class-driven designs which covers large amount of solutions with own issues that go far beyond the content of this paper. As for the maximization of the integration and inductive near-field power transfer in sub-GHz band, we can mentions for example Class-E half-wave zero $\mathrm{d} v / \mathrm{d} t$ rectifier (labeled as series-L VDR) that can benefit from a weak-coupled inductor and parasitics capacities of rectifier components [92], [93]. Simultaneously, it should be noted that current research of individual class-based solution is primarily focused on high-power applications and therefore, it is too early to discuss their feasibility for low-power $\mu \mathrm{W}$ applications, where many of IMDs belong. Class-E rectifier can be also readily find in many UHF applications.

In general, when the rectifier is implemented as a separate block, WPT system usually needs an auxiliary circuit (DC-DC converter or LDO) that performs two additional functions: 1 . modifies the voltage value and its time-domain response behaviour, and 2. can engages in assistance with fulfillment of the optimum load (see Sec. 2.2.2) condition. However, how can be observed from (2), with using the two-stage cascading conversion approach, the total efficiency is degraded much more because of multiplying relationship $\eta_{\mathrm{REC}} \eta_{\mathrm{DC}-\mathrm{DC}}$. For example, if we take quite optimistic values of $\eta_{\mathrm{REC}}=70 \%, \eta_{\mathrm{DC}-\mathrm{DC}}=80 \%$ for a rectifier and a DC-DC converter respectively, we get only $56 \%$ efficiency. Moreover, bulky energy storage components in DC-DC converters play against the effort of full integration of the harvesting system. To deals with this issue, the work by Kim brings interesting results $[61,94,95]$, where the rectifier and regulation process are combined into one block called Integrated Resonant Regulating Rectifier-IR ${ }^{3}$ (Fig. 6). Usage of active rectification in bridge and hybrid pulse modulation control has positive impact not only on the efficiency but also on fast regulation response. The $\mathrm{IR}^{3}$ design reports $\eta_{\mathrm{REC}} \eta_{\mathrm{DC}-\mathrm{DC}}$ up to $60 \%$ at $144 \mathrm{MHz}$ that is immediately reflected to the total prodigiously high WPT efficiency reaching up to $5 \%$ across $10 \mathrm{~mm}$ distance that is, according to our knowledge, probably the best confirmed result so far for low-power application with highly integration requirements, This work demonstrates a great potential of $R^{3}$ structure that is already wide-spread in many

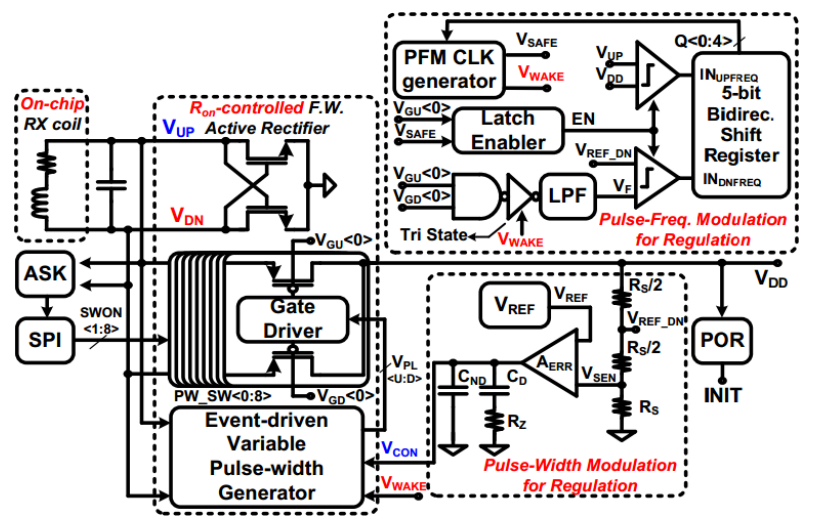

Fig. 6. Hybrid pulse modulation (HPM) with combined pulsewidth modulation (PWM) and pulse-frequency modulation (PFM) for integrated resonant rectification and regulation $\left(\mathrm{IR}^{3}\right)$ [61].

WPT applications [95]. Implementation of energy recycle technique and seamless-voltage/current-mode structures are other unexplored techniques where improvement in the efficiency and low-voltage behaviour can be found without affecting the design compactness or using off-the-shelf external components [96].

\subsubsection{PTE Issue}

The previous sections were dedicated to particular building blocks of a fully integrated WPT system. Nevertheless, the most significant factor, influencing the total efficiency i.e system level design, has been omitted so far. Since the most preferred approach in the current state of IMD research is near-field technique at the expense of significant deficiencies in far-field power transfer (see Sec. 2.1.1), this section is focused primarily on near-field resonant inductive coupling. However, all the knowledge presented here may be used with some caution for both. Despite the fact that there are some publications dealing with the design of IMDs using near-field resonant inductive coupling, the majority of works are based on system-independent analysis. In other words, only in the last few years, there is a starting trend to distinguish between the efficiency of four basic topologies for a dual-coil system (Fig. 7) with respect to the maximum power transport and maximum power transport efficiency-PTE. Those topologies are: SS topology, PS topology, SP topology, and PP topology, where the first (second) letter indicates the circuit arrangement on the source (load) side: S-series, P-parallel.

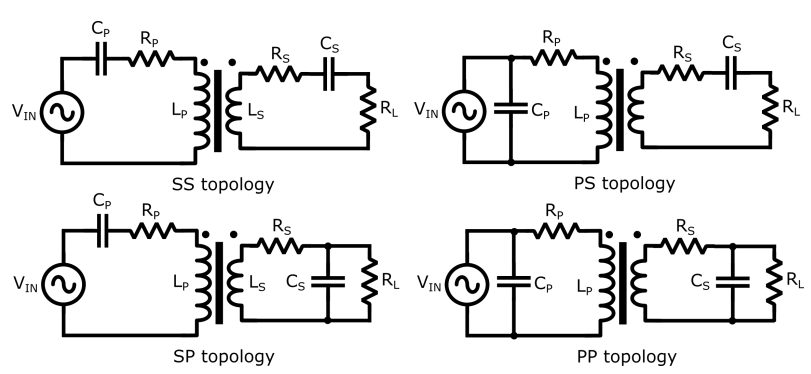

Fig. 7. The most widely used topologies for realization of an onchip integrated WPT system (inductor-less-capacitoronly matching solution). 
It has been shown that for the SP configuration with a high coupling coefficient, the intended maximization of power transport based on the standard resonant condition of the secondary coil can lead to its local minimum [97].

As well a general misconception is that the applying of maximum energy transport theorem, which is based on the mutual matching of input/output impedance (known as impedance matching theorem), also leads to an increase in the efficiency, which is of course not true. The maximum efficiency, in this case, is limited to $50 \%$. Thus, it is clear that system-level optimization is as important as the optimization of individual elements within the transport chain (link, OCAcoil, rectifier, etc.). System-level optimization itself can be realized on the basis of the following requirements:

- maximum power transport efficiency,

- maximum transferred (delivered to load) power,

- targeted compromise between the previous two requirements.

It is important to be aware of these requirements because in many works, only the PTE maximization is taken as the main goal.

In [98], Mr. Guo et al. report analytical expressions of the energy transport efficiency for individual WPT system configurations from Fig. 7. The authors also state that if the standard resonance condition on the secondary side of the WPT system is met, the efficiency expression does not depend on the topology choice on its primary side. However, as been mentioned before, applying a standard resonance condition on the secondary side does not necessarily lead to the optimum solution. Moreover, existence of socalled boundary frequency, above which the SS topology shows higher efficiency than the SP configuration and vice versa, was observed. A comprehensive analysis of SS and SP topologies in terms of the PTE and power transport is given in [97]. This work deals with finding suitable values of $C_{\mathrm{S}}$ and $C_{\mathrm{P}}$ capacitors. An important finding is that the SP topology is limited compared to the SS topology in terms of the maximum power transport to one optimum point (see Fig. 5 and Fig. 9 in [97]). At the same time, the authors provide an optimization-selection tool (figure of merit) for a trade-off between PTE and power transport, which is based on maximizing the weighted amount of the required PTE and the power transferred to load. Finding an optimization-selection tool for the SP topology is also the goal addressed in [99], where the authors utilize the maximized weighted multiplication of the efficiency and the transferred power using standard resonance conditions. The results include an improvement of the PTE from $44 \%$ (design for power transfer) to $72.5 \%$ (design for a compromise) at the original 90.2\% (design for PTE). Similarly, it is also valid in terms of the power delivered to load from $8.8 \mathrm{~mW}$ (design for PTE) to $177 \mathrm{~mW}$ (design for a compromise) at original $220 \mathrm{~mW}$ (design for power transfer). The same team later extended the proposed optimization-selection tool to three-coil and four-coil systems [100].
The great job in the context of making a certain order into quite messy and laborious approaches was done by $\mathrm{Mr}$. Zargham, who introduces consistent theorem of the optimum load/source for maximizing the PTE in a two-coil WPT system that represents very powerful analysis and optimization mechanism [62]. He analyzed inductive-based WPT system as a general 2-port model using scattering ( $S$ parameters), admittance ( $\mathrm{Y}$ parameters), impedance ( $\mathrm{Z}$ parameters), and hybrid (ABCD parameters) in the presence of two degrees of freedom created by two separated matching circuits (see Fig. 1). This can also be obtained by a multi-coil configuration [101]. The strength is hidden behind the versatility (independence on a chosen WPT topology) and straightforward application where the delivered power under the maximized PTE can be carefully tuned by the two matching circuits. In this way, the four topologies from Fig. 7 can be readily transformed and optimized.

The capacitor-only approach is gaining weight because quality factor of on-chip capacitors such as MIM (MetalInsulator-Metal) is several times greater than the quality of an on-chip inductor optimized for sub- $\mathrm{GHz}$ frequencies. Moreover, the inductor design is also more area-intensive that leads to highly inefficient design. In [102], a capacitoronly L-match approach for simultaneous power transferring to multiple devices was reported. Interested observations were reported in terms of the delivered power, sensitivity to load variation, responsiveness to the cross coupling, etc. In [62], Zargham brings very useful analysis by the investigation of parasitic effect of an additional matching component in L-match topologies that are preferred to be used in situations, where the quality factor of the matching network is not enforced and efficiency is of the primary concern. He derived generally valid formulas but his attention was focused mainly on SP-based topology i.e stepping-up impedance conversion at the source side and stepping-down at the load side (looking from load to source) as the most often scenario. This work also brings meaningful observation about the maximum ratio between $\operatorname{Re}\left\{Z_{\mathrm{L}}\right\}$ and $\operatorname{Re}\left\{Z_{\mathrm{L}(\mathrm{OPT})}\right\}$ to $\approx 21 \times$ (Fig. 1). This ratio is dedicated to a situation about increasing requirements on the matching capability of the rectifier input impedance $\operatorname{Re}\left\{Z_{\mathrm{L}}\right\}$ in the case of not to significantly breach the condition of 1-stage implementation under the optimum load condition. In terms of restriction on single capacitor-only matching, fully on-chip integration of a WPT system and the optimum load condition, approximate equality between the parasitic series resistance of coils $R_{\mathrm{S}}$ on the receiving side and load $\operatorname{Re}\left\{Z_{\mathrm{L}}\right\}$ should be respected. It is very important to note that this equality is valid only under conditions of a weakcoupled WPT system when losses in the transfer medium can be neglected and high Q capacitor is expected to be used. If this is not ensured, detailed information published in [62] should be taken into consideration.

In addition to what has been said so far, the finding and adaptively mapping $Z_{\mathrm{L}}$ impedance to $Z_{\mathrm{L}(\mathrm{OPT})}$, introduced also challenging area with a deeply anchored method in tuning the input impedance of a DC-DC converter varied by the 


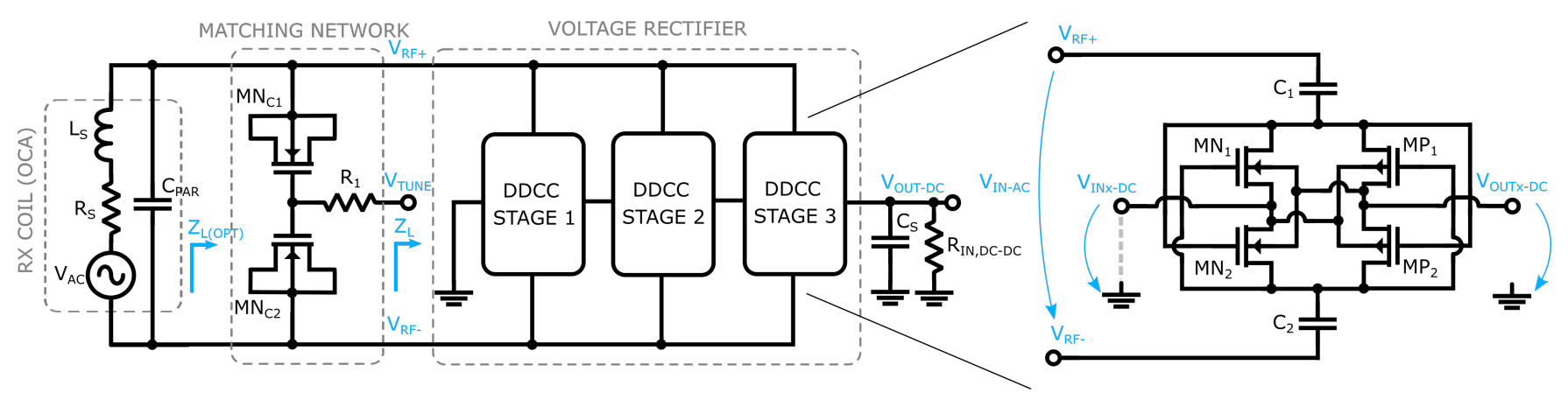

Fig. 8. Circuit diagram of the proposed WPT receiver.

maximum power point tracking (MPPT) algorithm [7]. The adaptively-varied input impedance of a DC-DC converter is then transferred across the rectifier to $Z_{\mathrm{L}}$. As an alternative, Q-Modulation technique [103] or other techniques that directly and suitably adjust $Z_{\mathrm{L}}$ to the extracted maximum power into the load, can be employed. However, one has to be always aware of the fact that the nonlinear rectifying element also generates currents and voltages at the harmonics of the input frequency, and although in this case, the output is in DC domain, the efficiency of the rectifier can be modified by terminating the harmonics. For these reasons, the small-signal analysis used in tradition-fashion can results to false estimation. To overcome this nuisance, usually harmonic balance methods are used for this purpose under numerical investigation [104]. In some cases (e.g. an ideal rectifier), methods like harmonic linearization in conjunction with Fourier analysis can be also employed to derive an analytical formula reflecting frequency behaviour of the input impedance [105]. In [59], a formula based on $\eta_{\text {REC }}$ and $\eta_{\text {REC-V }}$ parameters was used for investigation of effect of $Z_{\mathrm{L}}$ on the WPT performance. One can also find useful conclusions in [106] saying that "to maximize the power transfer and the amount of harvested power, the matching network must be designed to convert the small-signal input impedance calculated when input port is biased at the peak of input signal".

\section{WPT Design Example}

This section presents an example of WPT design with the fully integrated receiving part (rectenna - rectifying antenna) consisting of an OCA-coil (introduced in Sec. 2.1.2), where a weak coupling is expected and therefore, the lowvoltage operational capability of the rectifier was taken as priority. Through performed research, a differential drive cross-coupled (DDCC) CMOS bridge rectifier was found to be effective topology to deal with the low input voltage/power issues [89, 107-110].

The aim of the proposed rectifier was to further improve the performance of the DDCC rectifier topology for very low values of the input voltage. This was achieved by compensating the effect of threshold voltage $V_{\mathrm{TH}}$ of all the switching transistors. To improve the parameters of the rectifier from [89], the body-biasing technique is applied to NMOS transistors in addition to PMOS devices, as shown in the core cell depicted in Fig. 8 [111]. This has been made possible by the use of triple-well NMOS transistors in the design. By compensating $V_{\mathrm{TH}}$ of NMOS transistors, utilizing the generated DC voltage as the body-bias voltage, the performance of the rectifier is expected to improve also for very low values of the input voltage. It was shown in [111] that this topology provides an increase in the output power if compared to the topologies presented in [89], [107]. The negative effect of the proposed approach is a reduced PTE at higher values of the input power that is caused by excessive bias voltages reflecting to increased leakage and reverse currents, and therefore also increased loss. This rectifier stage forms the basis of the proposed receiver presented in thispaper.

\subsection{Proposed Receiver Architecture}

The circuit diagram of the proposed receiver is depicted in Fig. 8 [112]. The RX OCA-coil inductance, quality and self-resonance frequency were modelled based on the previously measured samples. Capacitor $C_{\mathrm{PAR}}$ together with two variable capacitors $M N_{C 1}$ and $M N_{C 2}$ form the parallel resonance capacitance - a part of the impedance matching circuit. These circuit elements were optimized to achieve the resonance frequency of $200 \mathrm{MHz}$ with the tuning voltage of around $250 \mathrm{mV}$. The rather large total span of the tunable capacitance allows us to adjust the rectifier input voltage depending on the receiver input conditions. This is done by tuning the resonator, if the input signal is weak, and detuning it, if the input signal becomes too strong. This ensures that the rectifier operates close to the optimum conditions.

Three rectifier stages are cascaded to provide the desired value of the output voltage (multiplication effect). This is done by connecting the DC input $V_{\mathrm{IN}(x+1)-\mathrm{DC}}$ of the next stage to the DC output $V_{\text {OUT } x-D C}$ of the previous one. The other part of the impedance matching is realized by the series input capacitance of the rectifier stages. Capacitor $C_{\mathrm{S}}$ serves

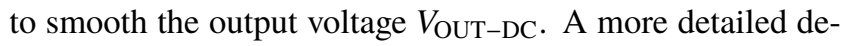
scription of the receiver including simulation results can be found in [112]. 
The receiver was designed and manufactured in a standard $130 \mathrm{~nm}$ CMOS technology, as part of an experimental prototype chip. The design of the RX OCA-coil was based on our work previously published in [69]. The final layout of the receiver, with its main parts highlighted, is depicted in Fig. 9. The total RX OCA-coil area is $1.16 \mathrm{~mm} \times 1.16 \mathrm{~mm}$. There are other circuits included in the area of the coil, as it was manufactured as part of a shared prototyping chip. These might have adverse effects on the OCA-coil performance, most notably increasing its parasitic capacitance and losses caused by eddy currents in crammed center (refer to degradation performance in Fig. 5).

\subsection{Measurement Results}

To facilitate measurement of the manufactured samples, the transmitter side of the WPT system has to be implemented as well. For this purpose, four versions of transmitter TX coils were implemented, based on the methods presented in [62], [113], with two coil sizes and two matching circuit topologies. A more detailed description of the TX coil and impedance matching design can be found in [114].

To minimize the influence of parasitic properties of a IC package on the measurement, bare die samples were used for the measurements. This necessitated the chip bonding to a small PCB that serves as a carrier. We also considered the possible effect of the chip seal ring on the RX OCA-coil. The seal ring forms another conductive loop around the RX OCAcoil and therefore, it has an negative effect on its parameters. To investigate this further, we prepared two versions of the samples to be evaluated. One includes the original chip as it was manufactured. The second version uses a modified version of the chip, which has the seal ring broken. This was achieved by a careful chip cutting at a sufficient distance from RX circuitry in order to avoid the chip damage. Photographs of the two sample versions are shown in Fig. 10.

So far, only preliminary measurement data is available. The measurement setup is not yet fully developed, therefore, the reported parameters are not final. Several problems arose during the building the measurement setup, mainly related to the bonding process and the TX coil tuning. These will be investigated further in the future. Nevertheless, the basic functionality of the system has been demonstrated.

Figure 11 shows the output voltage $V_{\text {OUT-DC }}$ and the output power $P_{\text {OUT-DC }}$ of the WPT system as a function of the rectifier load $R_{\mathrm{IN}, \mathrm{DC}-\mathrm{DC}}$ obtained by measurement for three different generator output power levels. Thus far, only one sample with the broken seal ring was evaluated, where the TX coil with the outer diameter of $24 \mathrm{~mm}$ and two-component matching network were used.

The maximum achieved $\eta_{\mathrm{MC}, \mathrm{T}} \eta_{\mathrm{LINK}} \eta_{\mathrm{MC}, \mathrm{R}} \eta_{\mathrm{REC}}$ efficiency in this measurement was $0.05 \%$. This is rather poor performance if compared to previously published works, e.g Kim's work in [95] or works in Tab. 2), where the peak efficiencies of up to $5 \%$ and around $1 \%$ were reported, respectively. Even if we factor in the different RX OCA-coil areas, the performance is below expectations. Reasons of poor performance are still under investigation but it is likely due to poor tuning of the TX coil, resulting in the operating frequency shift from $200 \mathrm{MHz}$ to $165 \mathrm{MHz}$. Likely, a redesign of the various PCBs used in the measurement setup will be needed in the future.

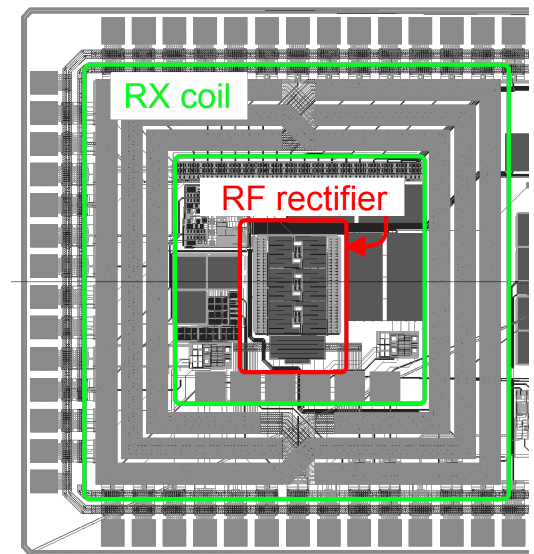

Fig. 9. Layout of the proposed RF wireless receiver. The area between the receiver coil (placed between the green rectangles) and the rectifier (placed inside the red rectangle) is filled by other circuits of the shared prototype chip.

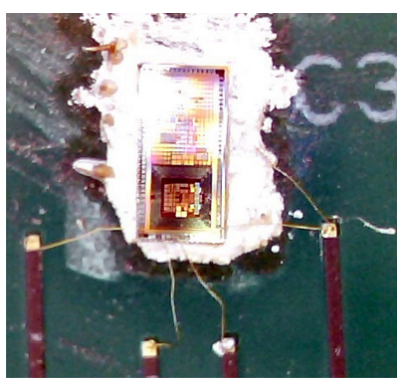

(a)

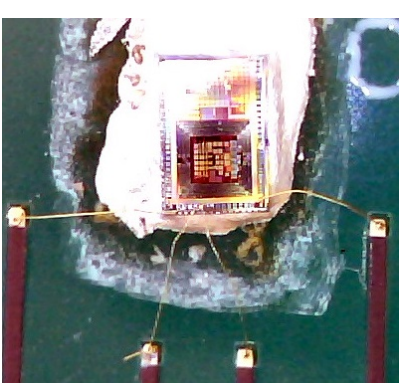

(b)
Fig. 10. Photographs of measurement samples: whole chip (a), chip with broken seal ring (b).

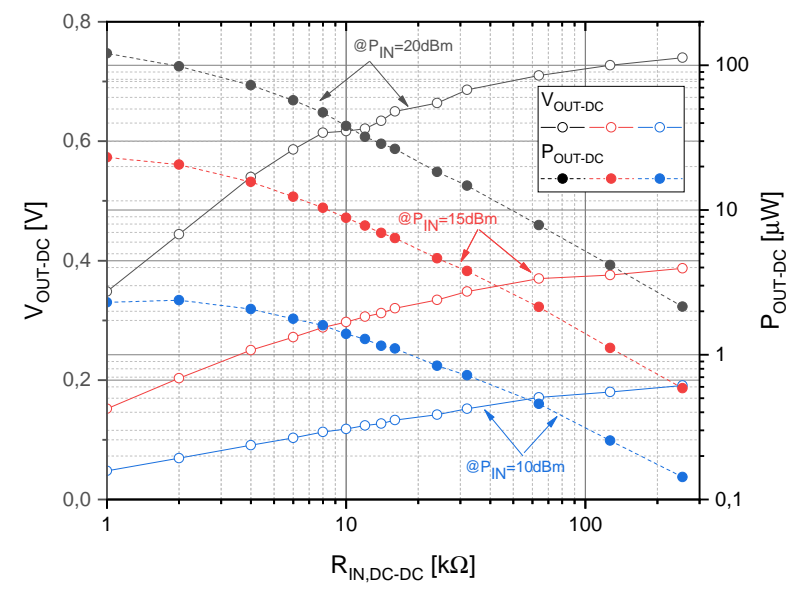

Fig. 11. Preliminary measurement results using the TX coil with $24 \mathrm{~mm}$ diameter and a sample with broken seal ring at TX to RX distance of $10 \mathrm{~mm}$ : rectified output voltage (left $y$-axis), output power (right $y$-axis) of the receiver as a function of load resistance (x-axis). 


\section{Conclusion}

Despite of the selected restrictions in long-distance energy transferring at the presence of loss-hungry environments such soft tissue is, the electromagnetic (EM) WPT can draw benefits from ad-hoc design in IC design phase without additional postprocessing steps needed, except for still present packaging/encapsulation process. Packaging can immediately influence the reliability, safety and cost. For this highly attractive reasons, challenges and problems that have to be solved within the design of a fully-integrated WPT system suitable for IMD applications are addressed in this paper. It has been shown that energy harvesters based on EM principle and fully realized in lossy silicon suffer from many issues that strictly limits their wider use. However, at the same time, it has been shown that they are still drifting in potential to be competitive with getting more and more popular alternatives as for example, ultrasound energy transferring that is dominant in brain monitoring and stimulating IMDs. To overcome current weaknesses of an on-chip EM WPT system, particularly present in standard IC processes, the area of interest in the future research should take into account the following observations: 1 . needed for biocompatible and biostable high $\varepsilon_{\mathrm{r}}$ materials for IC chip package/encapsulation, 2. deeper investigation of parasitic effect on OCA-coils in hundreds of $\mathrm{MHz}$ frequency band, 3. higher attention on the effective design of a regulated rectifier for near-field resonant inductive coupling with improved low-voltage behaviour, 4 . future high efficiency EM WPT system in presence of nearfield and especially, high lossy tissue should be designed for the optimum source/load theorem rather than the matching theorem (limited to $50 \%$ efficiency), 5. searching for novel and alternative solutions such as promising implementation of a booster antenna [63] or MIL implementation discussed in Sec. 2.1.1. Finally, we have to emphasize that information about individual system blocks present in this paper is strictly limited to fully on-chip WPT systems directly implemented on the IC chip in the meaning of clear SoC concept (especially for hundreds of $\mathrm{MHz}$ frequency band). In other words, e.g. if $\mathrm{SiP}$ approach is feasible or $\mathrm{GHz}$ frequency provide healthy conditions, the implementation of bulky active and high Q-passive components open additional amazing possibilities in the research field, which plays the major role in highly efficient design of EM WPT systems.

\section{Acknowledgments}

This work was supported in part by the Slovak Research and Development Agency under grant APVV-15 - 0254, the Ministry of Education, Science, Research and Sport of the Slovak Republic under grant VEGA 1/0905/17, and ECSEL JU under project PROGRESSUS (876868).

\section{References}

[1] WEI, X., LIU, J. Power sources and electrical recharging strategies for implantable medical devices. Frontiers of Energy and Power Engineering in China, 2008, vol. 2, no. 1, p. 1-13. DOI: 10.1007/s11708008-0016-3

[2] DETERRE, M. Toward an Energy Harvester for Leadless Pacemakers. Ph.D. Dissertation, Paris-Sud University, 2013.

[3] BASAERI, H., CHRISTENSEN, D. B., ROUNDY, S. A review of acoustic power transfer for bio-medical implants. Smart Materials and Structures, 2016, vol. 25, no. 12, p. 123001. DOI: 10.1088/09641726/25/12/123001

[4] AMAR, A. B., KOUKI, A. B., CAO, H. Power approaches for implantable medical devices. Sensors, 2015, vol. 15, no. 11, p. 28889-28914. DOI: $10.3390 / \mathrm{s} 151128889$

[5] XU, H., HANDWERKER, J., ORTMANNS, M. Telemetry for implantable medical devices: Part 2 - power telemetry. IEEE Solid-State Circuits Magazine, 2014, vol. 6, no. 3, p. 60-63. DOI: 10.1109/MSSC.2014.2327714

[6] SHI, B., LI, Z., FAN, Y. Implantable energy-harvesting devices. Advanced Materials, 2018, vol. 30, no. 44, p. 1801511. DOI: $10.1002 / \mathrm{adma} .201801511$

[7] TSUI, C.Y, LI, X., KI, W.H., et al. Energy harvesting and power delivery for implantable medical devices. Foundations and Trends in Electronic Design Automation, 2013, vol. 7, no. 3, p. 179-246. DOI: $10.1561 / 1000000029$

[8] SHARMA, T., NAIK, S., GOPAL, A., ZHANG, J.X. Emerging trends in bioenergy harvesters for chronic powered implants. MRS Energy \& Sustainability, 2015, vol. 2, p. E7. DOI: 10.1557/mre.2015.8

[9] SHI, B., LI, Z., FAN, Y. Implantable energy-harvesting devices. Advanced Materials, 2018, vol. 30, no. 44, p. 1801511. DOI: 10.1002/adma.201801511

[10] CHANDRAKASAN, A. P., VERMA, N., DALY, D. C. Ultralowpower electronics for biomedical applications. Annual Review of Biomedical Engineering, 2008, vol. 10, p. 247-274. DOI: 10.1146/annurev.bioeng.10.061807.160547

[11] RITTER, R., HANDWERKER, J., LIU, T., et al. Telemetry for implantable medical devices: Part 1-media properties and standards. IEEE Solid-State Circuits Magazine, 2014, vol. 6, no. 2, p. 47-51. DOI: 10.1109/MSSC.2014.2315052

[12] LU, F., ZHANG, H., MI, C. A review on the recent development of capacitive wireless power transfer technology. Energies, 2017, vol. 10, no. 11 , p. 1752 . DOI: $10.3390 /$ en 10111752

[13] AYAZIAN, S., HASSIBI, A. Delivering optical power to subcutaneous implanted devices. In IEEE International Conference of the Engineering in Medicine and Biology Society. Boston (USA), 2011, p. 2874-2877. DOI: 10.1109/IEMBS.2011.6090793

[14] AYAZIAN, S., AKHAVAN, V.A, SOENEN, E., et al. A photovoltaicdriven and energy-autonomous CMOS implantable sensor. IEEE Transactions on Biomedical Circuits and Systems, 2012, vol. 6, no. 4 , p. 336-343. DOI: 10.1109/TBCAS.2011.2179030

[15] DENISOV, A., YEATMAN, E. Ultrasonic vs. inductive power delivery for miniature biomedical implants. In International Conference on Body Sensor Networks. Singapore, 2010, p. 84-89. DOI: 10.1109/BSN.2010.27

[16] SANNI, A., VILCHES, A., TOUMAZOU, C. Inductive and ultrasonic multi-tier interface for low-power, deeply implantable medical devices. IEEE Transactions on Biomedical Circuits and Systems, 2012, vol. 6, no. 4, p. 297-308. DOI: 10.1109/TBCAS.2011.2175390 
[17] SHADID, R., NOGHANIAN, S. A literature survey on wireless power transfer for biomedical devices. International Journal of Antennas and Propagation, 2018, vol. 2018, p. 1-11 DOI: $10.1155 / 2018 / 4382841$

[18] WANG, M.L., BALTSAVIAS, S., CHANG, T.C., et al. Wireless data links for next-generation networked micro-implantables. In IEEE Custom Integrated Circuits Conference (CICC). San Diego (USA), 2018, p. 1-9. DOI: 10.1109/CICC.2018.8357096

[19] ERFANI, R., MAREFAT, F., SODAGAR, A.M, et al. Transcutaneous capacitive wireless power transfer (c-wpt) for biomedical implants. 2017 IEEE International Symposium on Circuits and Systems (IS CAS), 2017, p. 1-4, DOI: 10.1109/ISCAS.2017.8050940

[20] FERGUSON, J.E, REDISH, A.D. Wireless communication with implanted medical devices using the conductive properties of the body. Expert Review of Medical Devices, 2011, vol. 8, no. 4, p. 427-433. DOI: $10.1586 /$ erd.11.16

[21] DOVE, I. Analysis of Radio Propagation Inside the Human Body for in-Body Localization Purposes. Master's Thesis, University of Twente, 2014.

[22] ZARGHAM, M., GULAK, P. G. Fully integrated on-chip coil in 0.13 um CMOS for wireless power transfer through biological media. IEEE Transactions on Biomedical Circuits and Systems, 2015, vol. 9, no. 2, p. 259-271. DOI: 10.1109/TBCAS.2014.2328318

[23] RADIOM, S., MOHAMAADPOUR-AGHDAM, K., VANDENBOSCH, G.A.E., et al. A monolithically integrated on-chip antenna in $0.18 \mu \mathrm{m}$ standard CMOS technology for far-field short-range wireless powering. IEEE Antennas and Wireless Propagation Letters, 2010, vol. 9, p. 631-633. DOI: 10.1109/LAWP.2010.2052450

[24] RADIOM, S., BAGHAEI-NEJAD, M., MOHAMAADPOURAGHDAM, K., et al. Far-field on-chip antennas monolithically integrated in a wireless-powered 5.8-GHz downlink/uwb uplink rfid tag in $0.18-\mu \mathrm{m}$ standard CMOS. IEEE Journal of Solid-State Circuits, 2010, vol. 45, no. 9, p. 1746-1758. DOI: 10.1109/JSSC.2010.2055630

[25] POPPLEWELL, P., KARAM, V., SHAMIM, A., et al. A 5.2-GHz BFSK transceiver using injection-locking and an on-chip antenna. IEEE Journal of Solid-State Circuits, 2008, vol. 43, no. 4, p. 981-990. DOI: $10.1109 / \mathrm{JSSC} .2008 .917516$

[26] BEHDAD, N., SHI, D., HONG, W., et al. A $0.3 \mathrm{~mm}^{2}$ miniaturized $\mathrm{x}$-band on-chip slot antenna in $0.13 \mu \mathrm{m}$ CMOS. In IEEE Radio Frequency Integrated Circuits Symposium (RFIC). Honolulu (USA), 2007, p. 441-444. DOI: 10.1109/RFIC.2007.380919

[27] KIKKAWA, T. Gaussian monocycle pulse CMOS transmitter with on-chip integrated antenna and high-k dielectric slab waveguide. In IEEE 11th International Conference on Solid-State and Integrated Circuit Technology. Xi'an (China), 2012, p. 1-4. DOI: 10.1109/ICSICT.2012.6467712

[28] KULKARNI, V. V., MUQSITH, M., NIITSU, K., et al. A 750 Mb/s, $12 \mathrm{pJ} / \mathrm{b}, 6$-to-10 GHz CMOS IR-UWB transmitter with embedded on-chip antenna. IEEE Journal of Solid-State Circuits, 2009, vol. 44, no. 2, p. 394-403. DOI: 10.1109/JSSC.2008.2011034

[29] SUSLOV, M., TIMOSHENKO, A., LOMOVSKAYA, K. Survey and analysis of $0.18 \mu \mathrm{m}$ CMOS integrated antennas on $5.8 \mathrm{GHz}$ for RFD. In IX International Symposium on Telecommunications (BIHTEL). Sarajevo (Bosnia \& Herzegovina), 2012, p. 1-6. DOI: 10.1109/BIHTEL.2012.6412069

[30] LE, H., FONG, N., LUONG, H.C. RF energy harvesting circuit with on-chip antenna for biomedical applications. In International Conference on Communications and Electronics. Nha Trang (Vietnam), 2010, p. 115-117. DOI: 10.1109/ICCE.2010.5670693
[31] STOPJAKOVÁ, V., KOVAČ, M., ARBET, D., et al. Towards energyautonomous integrated systems through ultra-low voltage analog IC design. In 26th International Conference Mixed Design of Integrated Circuits and Systems (MIXDES). Rzeszow (Poland), 2019, p. 38-45. DOI: 10.23919/MIXDES.2019.8787196

[32] MERLI, F. Implantable Antennas for Biomedical Applications. EPFL, Technical Report, 2011.

[33] CHEEMA, H. M., SHAMIM, A. The last barrier: On-chip antennas. IEEE Microwave Magazine, 2013, vol. 14, no. 1, p. 79-91. DOI: 10.1109/MMM.2012.2226542

[34] KARIM, R., IFTIKHAR, A., IJAZ, B., et al. The potentials, challenges, and future directions of on-chip-antennas for emerging wireless applications - A comprehensive survey. IEEE Access, 2019, vol. 7, p. 173897-173934. DOI: 10.1109/ACCESS.2019.2957073

[35] KHALEGHI, A., CHÁVEZ-SANTIAGO, R., BALASINGHAM, I. An improved ultra wideband channel model including the frequencydependent attenuation for in-body communications. In Annual International Conference of the IEEE Engineering in Medicine and Biology Society. San Diego (USA), 2012, p. 1631-1634. DOI: 10.1109/EMBC.2012.6346258

[36] VOLAKIS, J. L., CHEN, C. C., FUJIMOTO K. Small Antennas: Miniaturization Techniques \& Applications. McGraw-Hill, 2010. ISBN: 978-0071625531

[37] SONG, Y., WU, Y., SUN, M., et al. An on-chip antenna integrated with a transceiver in $0.18-\mu \mathrm{m}$ CMOS technology. IEICE Electronics Express, 2017, vol. 14, no. 19, p. 20170836-20170836. DOI: $10.1587 /$ elex.14.20170836

[38] HOU, D., HONG, W., GOH, W., et al. D-band on-chip higherorder-mode dielectric-resonator antennas fed by half-mode cavity in CMOS technology. IEEE Antennas and Propagation Magazine, 2014, vol. 56, no. 3, p. 80-89. DOI: 10.1109/MAP.2014.6867684

[39] LIC., CHIU, T. 340-GHz low-cost and high-gain on-chip higher order mode dielectric resonator antenna for THz applications. IEEE Transactions on Terahertz Science and Technology, 2017, vol. 7, no. 3, p. 284-294. DOI: 10.1109/TTHZ.2017.2670234

[40] DENG, X., LI, Y., LIU, C., et al. $340 \mathrm{GHz}$ on-chip 3-D antenna with $10 \mathrm{dBi}$ gain and $80 \%$ radiation efficiency. IEEE Transactions on Terahertz Science and Technology, 2015, vol. 5, no. 4, p. 619-627. DOI: 10.1109/TTHZ.2015.2424682

[41] KHAN, W.T., CAGRI ULUSOY, A., DUFOUR, G., et al. A d-band micromachined end-fire antenna in 130-nm sige biCMOS technology. IEEE Transactions on Antennas and Propagation, 2015, vol. 63, no. 6, p. 2449-2459. DOI: 10.1109/TAP.2015.2416751

[42] BIJUMON, P.V., ANTAR, Y.M.M., FREUNDORFER, A.P., et al. Dielectric resonator antenna on silicon substrate for system on-chip applications. IEEE Transactions on Antennas and Propagation, 2008, vol. 56, no. 11, p. 3404-3410. DOI: 10.1109/TAP.2008.2005537

[43] BABAKHANI, A., GUAN, X., KOMIJANI, A., NATARAJAN, A., et al. A 77-GHz phased-array transceiver with on-chip antennas in silicon: Receiver and antennas. IEEE Journal of Solid-State Circuits, 2006, vol. 41, no. 12, p. 2795-2806. DOI: $10.1109 / \mathrm{JSSC} .2006 .884811$

[44] ALEXOPOULOS, N., JACKSON, D. Fundamental superstrate (cover) effects on printed circuit antennas. IEEE Transactions on Antennas and Propagation, 1984, vol. 32, no. 8, p. 807-816. DOI: $10.1109 /$ TAP.1984.1143433

[45] DISSANAYAKE, T., ESSELLE, K. P., YUCE, M. R. Dielectric loaded impedance matching for wideband implanted antennas. IEEE Transactions on Microwave Theory and Techniques, 2009, vol. 57, no. 10, p. 2480-2487. DOI: 10.1109/TMTT.2009.2029664 
[46] DISSANAYAKE, T., ESSELLE, K. P., YUCE, M. R. UWB antenna impedance matching in biomedical implants. In 2009 3rd European Conference on Antennas and Propagation. Berlin (Germany), 2009, p. 3523-3526. ISSN: $2164-3342$

[47] LIU Y. C. RF Energy Harvesting for Implantable ICS With on-Chip Antenna. Master's Thesis, University of Central Florida, 2014. Available at: http://purl.fcla.edu/fcla/etd/CFE0005202

[48] CHO, S., XUE, N., CAULLER, L., et al. A SU-8-based fully integrated biocompatible inductively powered wireless neurostimulator. Journal of Microelectromechanical Systems, 2013, vol. 22, no. 1, p. 170-176. DOI: 10.1109/JMEMS.2012.2221155

[49] FENG, P., CONSTANDINOU, T. G., YEON, P., et al. Millimeter-scale integrated and wirewound coils for powering implantable neural microsystems. In IEEE Biomedical Circuits and Systems Conference (BioCAS). Turin (Italy), 2017, p. 1-4. DOI: 10.1109/BIOCAS.2017.8325184

[50] YEON, P., MIRBOZORGI, S.A., ASH, B., et al. Fabrication and microassembly of a mm-sized floating probe for a distributed wireless neural interface. Micromachines, 2016, vol. 7, no. 9, p. 1-17. DOI: $10.3390 / \mathrm{mi} 7090154$

[51] BIEDERMAN, W., YEAGER, D.J., NAREVSKY, N., et al. A fullyintegrated, miniaturized $\left(0.125 \mathrm{~mm}^{2}\right) 10.5 \mu \mathrm{w}$ wireless neural sensor. IEEE Journal of Solid-State Circuits, 2013, vol. 48, no. 4, p. 960-970. DOI: 10.1109/JSSC.2013.2238994

[52] JOU, A. Y., PAJOUHI, H., AZADEGAN, R., et al. A CMOS integrated rectenna for implantable applications. In IEEE MTT-S International Microwave Symposium (IMS). San Francisco (USA), 2016, p. 1-3. DOI: 10.1109/MWSYM.2016.7540250

[53] RAHMANI, H., BABAKHANI, A. A dual-mode RF power harvesting system with an on-chip coil in 180-nm SOI CMOS for millimeter-sized biomedical implants. IEEE Transactions on Microwave Theory and Techniques, 2018, vol. 67, no. 1, p. 414-428. DOI: 10.1109/TMTT.2018.2876239

[54] OUDA, M. H. ARSALAN, M., MARNAT, L., et al. 5.2-GHz RF power harvester in $0.18 \mu \mathrm{m}$ CMOS for implantable intraocular pressure monitoring. IEEE Transactions on Microwave Theory and Techniques, 2013, vol. 61, no. 5, p. 2177-2184. DOI: $10.1109 /$ TMTT.2013.2255621

[55] ZARGHAM, M., GULAK, P.G. A $0.13 \mu \mathrm{m}$ CMOS integrated wireless power receiver for biomedical applications. In Proceedings of the ESSCIRC (ESSCIRC). Bucharest (Romania), 2013, p. 137-140. DOI: 10.1109/ESSCIRC.2013.6649091

[56] RAHMANI, H., BABAKHANI, A. A wireless power receiver with an on-chip antenna for millimeter-size biomedical implants in $180 \mathrm{~nm}$ SOI CMOS. IEEE MTT-S International Microwave Symposium (IMS). Honolulu (USA), 2017, p. 300-303. DOI: 10.1109/MWSYM.2017.8059103

[57] CABRRRA, F. L., DE SOUSA, F. R. Achieving optimal efficiency in energy transfer to a CMOS fully integrated wireless power receiver. IEEE Transactions on Microwave Theory and Techniques, 2016, vol. 64, no. 11, p. 3703-3713. DOI: 10.1109/TMTT.2016.2601916

[58] LU, X., WANG, P., NIYATO, D., et al. Wireless networks with RF energy harvesting: A contemporary survey. IEEE Соттиnications Surveys Tutorials, 2015, vol. 17, no. 2, p. 757-789. DOI: 10.1109/COMST.2014.2368999

[59] PARK, J., KIM, C., AKININ, A., et al. Wireless powering of mm-scale fully-on-chip neural interfaces. In IEEE Biomedical Circuits and Systems Conference (BioCAS). Turin (Italy), 2017, p. 1-4. DOI: 10.1109/BIOCAS.2017.8325186
[60] HA, S., AKININ, A., PARK, J., et al. A 16-channel wireless neural interfacing soc with RF-powered energy-replenishing adiabatic stimulation. In Symposium on VLSI Circuits (VLSI Circuits). Kyoto (Japan), 2015, p. C106-C107. DOI: 10.1109/VLSIC.2015.7231341

[61] KIM, C., HA, S., AKININ, A., et al. Design of miniaturized wireless power receivers for mm-sized implants. In IEEE Custom Integrated Circuits Conference (CICC). Austin (USA), 2017, p. 1-8. DOI: 10.1109/CICC.2017.7993703

[62] ZARGHAM, M., GULAK, P. G. Maximum achievable efficiency in near-field coupled power-transfer systems. IEEE Transactions on Biomedical Circuits and Systems, 2012, vol. 6, no. 3, p. 228-245. DOI: 10.1109/TBCAS.2011.2174794

[63] PACHLER, W., BOSCH, W., HOLWEG, G., et al. A novel booster antenna design coupled to a one square millimeter coil-on-chip RFID tag enabling new medical applications. In European Microwave Conference. Nuremberg (Germany), 2013, p. 1003-1006. DOI: 10.23919/EuMC.2013.6686829

[64] WANG, C., LIAO, H., XIONG, Y., et al. A physics-based equivalent-circuit model for on-chip symmetric transformers with accurate substrate modeling. IEEE Transactions on Microwave Theory and Techniques, 2009, vol. 57, no. 4, p. 980-990. DOI: 10.1109/TMTT.2009.2014479

[65] YUE, C. P. WONG, S. S. Physical modeling of spiral inductors on silicon. IEEE Transactions on Electron Devices, 2000, vol. 47, no. 3, p. 560-568. DOI: 10.1109/16.824729

[66] ZOU, W., ZENG, Y. An analytical series resistance model for on-chip stacked inductors with inclusion of proximity effect between stacked layers. In IEEE 11th International Conference on ASIC (ASICON). Chengdu (China), 2015, p. 1-4. DOI: 10.1109/ASICON.2015.7517081

[67] DANESH, M., LONG, J. R. Differentially driven symmetric microstrip inductors. IEEE Transactions on Microwave Theory and Techniques, 2002, vol. 50, no. 1, p. 332-341. DOI: $10.1109 / 22.981285$

[68] MURPhy, O. H., MCCARThy, K. G., DElabIE, C. J. P., et al. Design of multiple-metal stacked inductors incorporating an extended physical model. IEEE Transactions on Microwave Theory and Techniques, 2005, vol. 53, no. 6, p. 2063-2072. DOI: 10.1109/TMTT.2005.848813

[69] KOVÁČ, M., STOPJAKOVÁ, V., ARBET, D., et al. Investigation of on-chip coil in $130 \mathrm{~nm}$ standard CMOS for WPT and bio-applications. In International Conference on Emerging eLearning Technologies and Applications (ICETA). Vysoke Tatry (Slovakia), 2016, p. 177182. DOI: $10.1109 /$ ICETA.2016.7802071

[70] STOPJAKOVÁ, V., RAKUS, M., KOVÁČ, M., et al. Ultralow voltage analog IC design: Challenges, methods and examples. Radioengineering, 2018, vol. 27, no. 1, p. 171-185. DOI: $10.13164 /$ re.2018.0171

[71] ZHANG, Y., MA, D. B. Simo power converters with adaptive PCCM operation. Power Management Integrated Circuits. CRC Press, 2017, p. 71-97. DOI: 10.1201/9781315373362-3

[72] LEE, M., CHOI, Y., KIM, J. A 500-MHz, 0.76-w/mm ${ }^{2}$ power density and $76.2 \%$ power efficiency, fully integrated digital buck converter in 65-nm CMOS. IEEE Transactions on Industry Applications, 2016, vol. 52, no. 4, p. 3315-3323. DOI: 10.1109/TIA.2016.2541079

[73] WIBBEN, J., HARJANI, R. A high-efficiency DC-DC converter using $2 \mathrm{nH}$ integrated inductors. IEEE Journal of Solid-State Circuits, 2008, vol. 43, no. 4, p. 844-854. DOI: 10.1109/JSSC.2008.917321

[74] WENS, M., STEYAERT, M. Design and Implementation of FullyIntegrated Inductive DC-DC Converters in Standard CMOS. Springer Science \& Business Media, 2011. ISBN: 940071436X 
[75] KUO, N., ZHAO, B., NIKNEJAD, A. M. Novel inductive wireless power transfer uplink utilizing rectifier third-order nonlinearity. IEEE Transactions on Microwave Theory and Techniques, 2018, vol. 66, no. 1, p. 319-331. DOI: 10.1109/TMTT.2017.2700274

[76] LEE, H., GHOVANLOO, M. An integrated power-efficient active rectifier with offset-controlled high speed comparators for inductively powered applications. IEEE Transactions on Circuits and Systems I: Regular Papers, 2011, vol. 58, no. 8, p. 1749-1760. DOI: $10.1109 /$ TCSI.2010.2103172

[77] LAM, Y., KI, W., TSUI, C. Integrated low-loss CMOS active rectifier for wirelessly powered devices. IEEE Transactions on Circuits and Systems II: Express Briefs, 2006, vol. 53, no. 12, p. 1378-1382. DOI: $10.1109 /$ TCSII.2006.885400

[78] GUO, S., LEE, H. An efficiency-enhanced CMOS rectifier with unbalanced-biased comparators for transcutaneous-powered highcurrent implants. IEEE Journal of Solid-State Circuits, 2009, vol. 44 no. 6, p. 1796-1804. DOI: 10.1109/JSSC.2009.2020195

[79] ZHAO, J., GAO, Y. A 6.78-200 MHz offset-compensated active rectifier with dynamic logic comparator for $\mathrm{mm}$-size wirelessly powered implants. In IEEE Asian Solid-State Circuits Conference (A-SSCC). Tainan (Taiwan), 2018, p. 111-114. DOI: 10.1109/ASSCC.2018.8579325

[80] HASHEMI AGHCHEH BODY, S.S. High-Efficiency Low-Voltage Rectifiers for Power Scavenging Systems. Ph.D. Dissertation, École Polytechnique de Montréal, 2011. Available at: https://publications.polymtl.ca/649

[81] MAHMOUD, M., ABDEL-RAHMAN, A. B., FAHMY, G. A., et al. Dynamic threshold compensated, low voltage CMOS energy harvesting rectifier for UHF applications. In IEEE 59th International Midwest Symposium on Circuits and Systems (MWSCAS). Abu Dhabi (United Arab Emirates), 2016, p. 1-4. DOI: 10.1109/MWSCAS.2016.7870052

[82] KAMALINEJAD, P., KEIKHOSRAVY, K., MIRABBASS, S., et al. An efficiency enhancement technique for CMOS rectifiers with low start-up voltage for UHF RFID. In International Green Computing Conference Proceedings. Arlington (USA), 2013, p. 1-6. DOI: 10.1109/IGCC.2013.6604483

[83] BAKHHTIAR, A. S., JALALI, M. S. MIRABBASS, S. A highefficiency CMOS rectifier for low-power RFID tags. In IEEE International Conference on RFID. Orlando (USA), 2010, p. 83-88. DOI: 10.1109/RFID.2010.5467271

[84] PAN, D., ZHANG, F., HUANG, L., et al. A common-gate bootstrapped CMOS rectifier for VHF isolated DC-DC converter Journal of Semiconductors, 2017, vol. 38, no. 5, p. 055002. DOI: $10.1088 / 1674-4926 / 38 / 5 / 055002$

[85] HASHEMI, S. S., SAWAN, M., SAVARIA, Y. A high-efficiency lowvoltage CMOS rectifier for harvesting energy in implantable devices. IEEE Transactions on Biomedical Circuits and Systems, 2012, vol. 6 , no. 4, p. 326-335. DOI: 10.1109/TBCAS.2011.2177267

[86] PETERS, C., HANDWERKER, J., HENRICI, F., et al. Experimental results on power efficient single-poly floating gate rectifiers. In IEEE International Symposium on Circuits and Systems. Taipei (Taiwan), 2009, p. 1097-1100. DOI: 10.1109/ISCAS.2009.5117951

[87] MANDAL, S., SARPESHKAR, R. Low-power CMOS rectifier design for RFID applications. IEEE Transactions on Circuits and Systems I: Regular Papers, 2007, vol. 54, no. 6, p. 1177-1188. DOI: 10.1109/TCSI.2007.895229

[88] KAMALINEJAD, P., KEIKJOSRAVY, K., MIRABBASI, S., et al. A CMOS rectifier with an extended high-efficiency region of operation. In IEEE International Conference on RFID-Technologies and Applications (RFID-TA). Johor Bahru (Malaysia), 2013, p. 1-6. DOI: 10.1109/RFID-TA.2013.6694527
[89] MOGHADDAM, A. K., CHUAH, J. H., RAMIAH, H., et al. A 73.9\%-Efficiency CMOS rectifier using a lower DC feeding (LDCF) self-body-biasing technique for far-field RF energyharvesting systems. IEEE Transactions on Circuits and Systems I: Regular Papers, 2017, vol. 64, no. 4, p. 992-1002. DOI: $10.1109 /$ TCSI.2016.2623821

[90] TSAI, J., KUO, C., LIN, S., et al. A wirelessly powered CMOS electrochemical sensing interface with power-aware RFDC power management. IEEE Transactions on Circuits and Systems I: Regular Papers, 2018, vol. 65, no. 9, p. 2810-2820. DOI: $10.1109 /$ TCSI.2018.2797238

[91] JENDERNALIK, W., JAKUSZ, J., BLAKIEWICZ, G., et al. A high-efficient low-voltage rectifier for CMOS technology. Metrology and Measurement Systems, 2016, vol. 23, no. 2, p. 261-268. DOI: $10.1515 / \mathrm{mms}-2016-0017$

[92] MA, Q., HAIDER, M. R., MASSOUD, Y. Low-loss rectifier for RF powering of implantable biosensing devices. In IEEE Wireless Microwave Technology Conference (WAMICON). Cocoa Beach (USA), 2012, p. 1-4. DOI: 10.1109/WAMICON.2012.6208452

[93] KKELIS, G., YATES, D. C., MITCHESON, P. D. Class-E halfwave zero dv/dt rectifiers for inductive power transfer. IEEE Transactions on Power Electronics, 2017, vol. 32, no. 11, p. 8322-8337. DOI: 10.1109/TPEL.2016.2641260

[94] KIM, C., PARK, J., AKININ, A., et al. A fully integrated $144 \mathrm{MHz}$ wireless-power-receiver-on-chip with an adaptive buck-boost regulating rectifier and low-loss h-tree signal distribution. In IEEE Symposium on VLSI Circuits (VLSI-Circuits). Honolulu (USA), 2016, p. 1-2. DOI: 10.1109/VLSIC.2016.7573492

[95] KIM, C., HA, S., PARK, J., et al. A 144-MHz fully integrated resonant regulating rectifier with hybrid pulse modulation for $\mathrm{mm}$-sized implants. IEEE Journal of Solid-State Circuits, 2017, vol. 52, no. 11, p. 3043-3055. DOI: 10.1109/JSSC.2017.2734901

[96] SADEGHI GOUGHERI, H., KIANI, M. An inductive voltage/current-mode integrated power management with seamless mode transition and energy recycling. IEEE Journal of Solid-State Circuits, 2019, vol. 54, no. 3, p. 874-884. DOI: 10.1109/JSSC.2018.2884322

[97] HALPERN, M. E., NG, D. C. Optimal tuning of inductive wireless power links: Limits of performance. IEEE Transactions on Circuits and Systems I: Regular Papers, 2015, vol. 62, no. 3, p. 725-732. DOI: $10.1109 /$ TCSI.2014.2386771

[98] GUO, Y., ZHU, D., JEGADEESAN, R. Inductive wireless power transmission for implantable devices. In International Workshop on Antenna Technology (iWAT). Hong Kong (China), 2011, p. 445-448. DOI: 10.1109/IWAT.2011.5752354

[99] KIANI, M., GHOVANLOO, M. A figure-of-merit for design of high performance inductive power transmission links for implantable microelectronic devices. In Annual International Conference of the IEEE Engineering in Medicine and Biology Society. San Diego (USA), 2012, p. 847-850. DOI: 10.1109/TIE.2012.2227914

[100] KIANI, M. GHOVANLOO, M. A figure-of-merit for designing highperformance inductive power transmission links. IEEE Transactions on Industrial Electronics, 2013, vol. 60, no. 11, p. 5292-5305. DOI: 10.1109/TIE.2012.2227914

[101] SEO, D. W., LEE, J. H., LEE, H. S. Study on two-coil and four-coil wireless power transfer systems using z-parameter approach. ETRI Journal, 2016, vol. 38, no. 3, p. 568-578. DOI: $10.4218 /$ etrij.16.0115.0692

[102] KIM, J., KIM, D., PARK, Y. Analysis of capacitive impedance matching networks for simultaneous wireless power transfer to multiple devices. IEEE Transactions on Industrial Electronics, 2015, vol. 62, no. 5, p. 2807-2813. DOI: 10.1109/TIE.2014.2365751 
[103] KIANI, M., LEE, B., YEON, P., et al. A q-modulation technique for efficient inductive power transmission. IEEE Journal of Solid-State Circuits, 2015, vol. 50, no. 12, p. 2839-2848. DOI: 10.1109/JSSC.2015.2453201

[104] VISSER, H. J., KEYROUZ, S., SMOLDERS, A. B. Optimized rectenna design. Wireless Power Transfer, 2015, vol. 2, no. 1, p. 44-50. DOI: $10.1017 /$ wpt.2014.14

[105] SUN, J., KARIMI, K. J. Small-signal input impedance modeling of line-frequency rectifiers. IEEE Transactions on Aerospace and Electronic Systems, 2008, vol. 44, no. 4, p. 1489-1497. DOI: 10.1109/TAES.2008.4667724

[106] HAMEED, Z., MOEZ, K. Design of impedance matching circuits for rf energy harvesting systems. Microelectronics Journal, 2017, vol. 62, p. 49-56. DOI: 10.1016/j.mejo.2017.02.004

[107] KOTANI, K., ITO, T. High efficiency CMOS rectifier circuit with self-Vth-cancellation and power regulation functions for UHF RFIDs. In IEEE Asian Solid-State Circuits Conference. Jeju (South Korea), 2007, p. 119-122. DOI: 10.1109/ASSCC.2007.4425746

[108] DAI, H., LU, Y., LAW, M. K., et al. A review and design of the on-chip rectifiers for RF energy harvesting. In IEEE International Wireless Symposium (IWS). Shenzhen (China), 2015, p. 1-4. DOI: 10.1109/IEEE-IWS.2015.7164642

[109] YEO, K. H., ALI, S. H. M., MENON, P.S., et al. Comparison of CMOS rectifiers for micropower energy harvesters. 2015 IEEE Conference on Energy Conversion (CENCON). Johor Bahru (Malaysia), 2015, p. 419-423. DOI: 10.1109/CENCON.2015.7409581

[110] KAROLAK, D., TARIS, T., DEVAL, Y., et al. Design comparison of low-power rectifiers dedicated to RF energy harvesting. In 19th IEEE International Conference on Electronics, Circuits, and Systems (ICECS). Seville (Spain), 2012, p. 524-527. DOI: 10.1109/ICECS.2012.6463693

[111] POTOČNÝ, M., STOPJAKOVÁ, V., KOVÁČ, M. Self Vthcompensating CMOS on-chip rectifier for inductively powered implantable medical devices. In IEEE 21st International Symposium on Design and Diagnostics of Electronic Circuits and Systems (DDECS). Budapest (Hungary), 2018, p. 158-161. DOI: 10.1109/DDECS.2018.00035

[112] POTOČNÝ, M., KOVÁC̆, M., ARBET, D., et al. A $200 \mathrm{MHz}$ RF wireless power transfer receiver for implantable medical devices fully integrated in $130 \mathrm{~nm}$ CMOS. In 16th Biennial Baltic Electronics Conference (BEC). Tallinn (Estonia), 2018, p. 1-5. DOI: 10.1109/BEC.2018.8600988
[113] FINKENZELLER, K. RFID Handbook: Fundamentals and Applications in Contactless Smart Cards, Radio Frequency Identification and Near-Field Communication. 3rd ed. Hoboken, NJ: Wiley, 2010. ISBN: 9780471988519

[114] POTOČNÝ, M., STOPJAKOVÁ, V., KOVÁČ, M. Measurement of a wireless power transfer system with a fully integrated receiver. In 17th International Conference on Emerging eLearning Technologies and Applications (ICETA). Stary Smokovec (Slovakia), 2019, p. 655-660. DOI: 10.1109/ICETA48886.2019.9039985

\section{About the Authors}

Viera STOPJAKOVÁ received the M.Sc. and the Ph.D. degrees in Microelectronics from Slovak University of Technology in Bratislava, Slovakia in 1992 and 1997, respectively. Currently, she is a full-time Professor at the Institute of Electronics and Photonics of the same university. She has been involved in more than 20 international and national research projects under different funding schemes. She has published over 200 papers in various scientific journals and conference proceedings; and she is a co-inventor of two US patents in the field of on-chip supply current testing. Her main research interests include IC design and test, low-voltage analog IC design, smart sensors, on-chip energy harvesting and biomedical monitoring.

Martin KOVÁ $\breve{C}$ received his M.S. and the Ph.D. degrees in Electronics from Slovak University of Technology in Bratislava, Slovakia in 2013 and 2018, respectively. He is currently a Postdoc at Institute of Electronics and Photonics of the same university. His research is focused on lowvoltage and low-power analog IC, UWB antenna design, onchip parametric testing, and energy-efficient RF integrated systems for biomedical applications.

Miroslav POTOČNÝ received the M.S. degree in Electronics from Slovak University of Technology in Bratislava, Slovakia in 2016. Since September 2016 he has been a Ph.D. student at the Institute of Electronics and Photonics of the same university. His main research interest is design of RF integrated circuits. 